\title{
Caracterización espacio-temporal de la distribución del arsénico en un acuífero kárstico en el sur del Estado de México
}

\author{
Spatio-temporal characterization of arsenic distribution in a karst aquifer in the south of the State \\ of Mexico
}

Humberto Burgos ${ }^{1, *}$, Jaime Gárfias ${ }^{1}$, Richard Martel $^{2}$, Javier Salas-García

${ }^{1}$ Instituto Interamericano de Tecnología y Ciencias del Agua (IITCA). Universidad Autónoma del Estado de México, 50295, Toluca,

${ }^{2}$ Institut National de la Recherche Scientifique (INRS-ETE), 490 Rue de la Couronne, Québec G1K 9A9, Canadá.

${ }^{3}$ Facultad de Ingeniería (FI-UAEM), Universidad Autónoma del Estado de México, 50100, Toluca, Edo. México, México.

* Autor para correspondencia: (H. Burgos) hburgoshuezo@gmail.com Edo. México, México.

\section{RESUMEN}

Diversidad de factores antropogénicos, geológicos y climáticos están relacionados con la conformación de las propiedades fisicoquímicas del agua subterránea en una zona específica, los cuales deben de ser estudiados utilizando los enfoques adecuados. Para lograrlo, el objetivo principal de esta investigación estuvo dirigido a evaluar la situación actual del recurso, enfatizando en la individualización de los principales factores que determinan su evolución espacio temporal en los municipios de Ixtapan de la Sal y Tonatico. El enfoque metodológico utilizado consistió en la combinación de técnicas de análisis hidroquímico, estadístico multivariado y geoestadístico, aplicadas a los parámetros fisicoquímicos medidos en fuentes termales, no termales, superficiales y pozos. Para 2015 y 2019, los resultados muestran que dos tipos de agua predominan: $\mathrm{Ca}^{2+}-\mathrm{HCO}_{3}^{-}$y $\mathrm{Na}^{+}-\mathrm{Cl}$. Un tercer grupo, $\mathrm{Ca}^{2+}-\mathrm{Mg}^{2+}-\mathrm{Cl}$, evidencia procesos de mezcla entre aguas termales y no termales. Adicionalmente, la disolución de halita, minerales carbonatados (dolomita y calcita) y de sulfato de magnesio es predominante en la conformación iónica mayoritaria. El Análisis de componentes principales confirma dos procesos de importancia: (1) salinidad y (2) alcalinidad, relacionados a factores geogénicos y antropogénicos. La modelación geoestadística, realizada por el kriging ordinario, muestra que la calidad del agua decrece en dirección sur-oeste hacia el nor-este, involucrando al arsénico como principal limitante de calidad. Puede concluirse que un abordaje combinado, que incluya análisis hidroquímico y técnicas estadísticas, ofrece una alternativa viable para el estudio de la evolución fisicoquímica del agua subterránea, cuya implementación puede ser extrapolable a acuíferos de similar naturaleza.

La revisión por pares es responsabilidad de la Universidad Nacional Autónoma de México.
Palabras clave: Geoestadística, Análisis de componentes principales, Arsénico, hidrogeoquímica, Ixtapan de la Sal, Tonatico.

\section{ABSTRACT}

Diversity of anthropogenic, geological and climatic factors are related to the conformation of the physicochemical properties of groundwater in a specific area, which should be studied using appropriate approaches. To achieve this, the main objective of this research was aimed at assessing the current situation of the resource emphasizing the individualization of the main factors that determine its temporal-space evolution in the municipalities of Ixtapan de la Sal and Tonatico. The methodological approach used consisted of a combination of hydrochemical, multivariate statistical and geostatistical analysis techniques, applied to the physicochemical parameters measured in thermal, non-thermal, surface sources and wells. For 2015 and 2019, the results show that two types of water predominate: $\mathrm{Ca}^{2+}-\mathrm{HCO}_{3}^{-}$and $\mathrm{Na}^{+}-\mathrm{Cl}$. A third group, $\mathrm{Ca}^{2+}-\mathrm{Mg}^{2+}-\mathrm{Cl}$, evidences mixing processes between thermal and non-thermal waters. Additionally, the dissolution of halite, carbonate minerals (dolomite and calcite) and magnesium sulfate is predominant in the majority ionic conformation. Principal components analysis confirms two important processes: (1) salinity and (2) alkalinity, related to geogenic and anthropogenic factors. The geostatistical modeling, carried out by ordinary kriging, showe that water quality decreases in a south-west to north-east direction, involving arsenic as the main quality limitation factor. It can be concluded that a combined approach, which includes hydrochemical analysis and statistical techniques, offers a viable alternative for the study of the physicochemical evolution of groundwater, the implementation of which can be extrapolated to aquifers of a similar nature.

Keywords: Geostatistics, Principal Components Analysis, Arsenic, Hydrogeochemistry, Ixtapan de la Sal, Tonatico. 


\section{Introducción}

La calidad del agua utilizada para consumo humano ha recibido especial atención a lo largo de los años por los posibles riesgos a la salud asociados a la presencia de factores bióticos y abióticos, entre los que destaca el arsénico como factor limitante por sus características de toxicidad. Su presencia en el agua de consumo puede deberse a factores antropogénicos, relacionados con las actividades vinculadas al aprovechamiento de los recursos que la naturaleza provee, así como a factores geogénicos, a partir de los materiales que conforman el acuífero y que introducen en él concentraciones variables del metaloide. Bajo esta perspectiva, en diversas partes del mundo el estudio de la influencia que estos factores tienen sobre la calidad del agua ha sido tema de estudio, puesto que muchas regiones presentan condiciones inherentes que permiten la contaminación por arsénico y otros elementos, ya sea por la acción individual o conjunta de los medios antes mencionados.

En tal sentido, el manejo sustentable de los recursos hídricos implica la profundización en el conocimiento de los mecanismos que determinan la composición fisicoquímica del recurso, así como de los procesos que intervienen en su evolución espacio temporal. Sin embargo, Jeong (2001) afirma que, a partir de la información de composición química del agua, no es fácil distinguir entre los aportes geogénicos y aquellos de naturaleza antropogénica. Por ello, diversos métodos han sido propuestos para la evaluación de la calidad del agua, así como de los factores y mecanismos que en ella intervienen. De esta forma, investigaciones orientadas hacia la determinación del origen de los constituyentes del agua han sido desarrolladas. Ortega-Guerrero (2009) incluye metodologías de análisis de isótopos estables y radioactivos, así como análisis geoquímico y su modelación, como una aproximación a los mecanismos responsables de la presencia de arsénico y flúor en la Cuenca de la Independencia, Estado de Guanajuato. Investigaciones adicionales intentan superar la limitante antes identificada introduciendo técnicas de análisis estadístico multivariado para identificar el origen de los constituyentes del agua en la región de Andhra Pradesh, India (Subba-Rao et al. 2007). Estas experiencias muestran que, a pesar de responder a un contexto y problemática específicos, existe una dispersión de las metodologías relacionadas a evaluar la evolución de la información hidrogeoquímica de una zona.

Muestras de esta dispersión pueden ser encontradas, de igual forma, en la literatura relacionada a la zona de estudio. Considérese, por ejemplo, que existen aún limitantes en la metodología de abordaje realizada, a pesar de los esfuerzos de investigación realizados por Esteller et al. (2019) y Martínez-Florentino (2015), quienes se enfocan hacia el estudio de los procesos de mezcla entre aguas termales y no termales, así como al establecimiento de los patrones hidroquímicos de los diferentes tipos de agua en los municipios de Ixtapan de la Sal y Tonatico. En este sentido, ninguno de ellos incorpora técnicas adicionales que retomen dos aspectos fundamentales: (1) el posible origen iónico mayoritario y (2) la identificación e individualización de los factores involucrados en la composición fisicoquímica del agua y su distribución y evolución espacio-temporal. Estos análisis, en conjunto, podrían brindar una herramienta importante en la gestión integral del recurso, enfocada hacia la toma de decisiones para su aprovechamiento, dando la pauta para considerar que técnicas adicionales que permitan consolidar y unificar dicho proceso de evaluación pueden ser incorporadas.

Bajo esta condición y el contexto antes mencionados, así como para superar las limitantes metodológicas de abordaje de caracterización hidroquímica ya identificadas, el principal objetivo de esta investigación fue evaluar los factores que controlan la evolución geoquímica del agua en la región Ixtapan de la Sal-Tonatico, Estado de México. Para tal fin, el enfoque de la investigación incluyó el uso combinado de herramientas de análisis hidroquímico y estadísticas orientadas hacia el cumplimiento de las siguientes metas: (1) proveer información para establecer una comparación 
evolutiva temporal de la calidad del recurso, (2) identificar los principales mecanismos de enriquecimiento iónico y de composición fisicoquímica y (3) definir la distribución espacio-temporal de estos mecanismos en la zona de estudio. Los resultados muestran la utilidad del enfoque empleado, no solamente para establecer los principales mecanismos involucrados en la composición fisicoquímica del agua, sino también para consolidarse en una herramienta combinada que posibilita la predicción de la situación evolutiva de la calidad del recurso en áreas para las cuales no se cuenta con un monitoreo, y cuya experiencia podría ser extrapolable a acuíferos de similar naturaleza a la aquí abordada.

\section{Trabajos previos}

Los procesos hidrogeoquímicos que tienen lugar en un acuífero han sido tema de estudio en las últimas décadas, siendo evaluados desde diversas metodologías que vuelven disperso, en muchas ocasiones, el abordaje de la evolución fisicoquímica del agua. En este sentido, Srinivas et al. (2017) desarrollaron un método para determinar la idoneidad del agua para uso agrícola y consumo humano en Tamil Nadu, India, considerando la comparación de los resultados analíticos con estándares nacionales e internacionales. Realizaron, adicionalmente, el trazado de diagramas bidimensionales, con el objetivo de determinar la adecuación del agua para riego y los mecanismos involucrados en su composición química. Estos autores aplicaron técnicas útiles para la determinación de la calidad, sin el involucramiento de la variable de evolución temporal ni la participación de la relación existente entre los elementos químicos analizados.

Minvielle et al. (2015) abordan la evolución espacio-temporal de las características fisicoquímicas en un sistema kárstico en el condado de Vaucluse al sureste de Francia. Ellos proponen un enfoque, principalmente, estadístico en el abordaje de dicha evolución. En ese sentido, incorporan las técnicas de Análisis de componentes principales y de la distribución de frecuencias (CFD), así como los métodos de la presión parcial del dióxido de carbono y el índice de saturación con respecto a la calcita, como una forma de medir la variación espacial de la calidad del agua. El objetivo de esta investigación fue evaluar el grado de desarrollo de la red de karstificación para identificar su vulnerabilidad a una posible contaminación. Sus resultados muestran que, a partir de la metodología empleada, pueden identificarse tanto los diferentes tipos de agua como las condiciones de flujo en un sistema, pudiendo estimarse así el desarrollo de la red kárstica, consolidándose en un aporte para la evaluación de la vulnerabilidad de los mismos.

En un estudio adicional realizado en el sur de España, Sánchez et al. (2015) retoman la aplicabilidad del análisis de distribución de frecuencias (CFD) en estudios de hidroquímica. El objetivo de esta investigación estuvo dirigido hacia la individualización de las condiciones hidrológicas y meteorológicas que influyen en el flujo de los manantiales. Se identifica en este enfoque metodológico, respecto del aplicado por Srinivas et al. (2017), la limitante del requerimiento de un número alto de muestreos, lo que constituye un factor importante que restringe su aplicación.

Un trabajo particularmente interesante, en términos de aporte al estudio de hidroquímica, es el llevado a cabo por Valdes et al. (2007), quienes realizaron un multienfoque para el abordaje de un acuífero kárstico en la región Alta Normandía (Haute-Normandie-Francia), basado, principalmente, en técnicas estadísticas como aproximación a la caracterización hidrogeoquímica del acuífero. Sin embargo, dicha investigación tuvo como propósito interpretar la distribución espacial de los resultados de geoquímica para determinar los factores que la controlan y entender el rol del flujo y estructura del acuífero en la composición geoquímica. Con el enfoque utilizado, concluyen, pueden demostrar que el uso de las correlaciones espaciales y cruzadas permite el análisis de la distribución de las características geoquímicas en dicha zona de estudio. 
Bajo la premisa de este último enfoque, puede establecerse que un abordaje multivariable, que integre los aspectos de variación hidroquímica, en el sentido temporal y espacial, se considera como el más apropiado para fines de evaluación del funcionamiento de acuíferos kársticos, esto dadas sus características propias que dificultan su abordaje desde los métodos de investigación tradicionales (Sánchez et al., 2015). Un enfoque común, que integra los elementos antes mencionados, se basa en la combinación del establecimiento de relaciones químicas para establecer el origen iónico del agua asociado a herramientas de análisis estadístico multivariado y de geoestadística, lo que permite definir la evolución, en espacio y tiempo, de los principales factores involucrados en la composición fisicoquímica del agua (Jeong, 2001; Sánchez-Martos et al., 2001; Satyaji-Rao et al., 2010; Ma et al., 2014). En este sentido, la presente investigación sigue la misma tendencia multienfoque, considerando las ventajas que se logran en la caracterización de los procesos que determinan la calidad del agua y que han sido destacados por las investigaciones antes mencionadas.

\section{Descripción del área de estudio}

El área de estudio abarca los municipios de Ixtapan de la Sal y Tonatico (Figura 1). Con una extensión territorial de $255 \mathrm{~km}^{2}$, equivalente al $0.92 \%$ del territorio estatal, se encuentra ubicada en la zona sur del Estado de México y está enclavada en la cuenca del río Balsas, entre los paralelos $18^{\circ} 55^{\prime} 30^{\prime \prime}$ y $18^{\circ} 42^{\prime} 0^{\prime \prime}$ de latitud norte y entre los meridianos 99³4'30" y 9946’53" longitud oeste. El clima, de acuerdo a la clasificación climática de Köppen, es templado subhúmedo hacia el norte (Cwbg), en tanto que, hacia el sur, es semicálido subhúmedo con lluvias en verano $(\mathrm{A}(\mathrm{C}) \mathrm{wg})$ y lluvia invernal inferior al 5\%. Su temperatura media anual oscila entre $\operatorname{los} 15^{\circ} \mathrm{C}$ y los $20^{\circ} \mathrm{C}$, con una máxima de $31^{\circ} \mathrm{C}$ y una mínima de $6^{\circ} \mathrm{C}$. La presencia de aguas termales en la zona produce un doble efecto: en primer lugar, la generación de un polo de desarrollo, expresado en la inversión en infraestructura para el aprovechamiento de la misma, y, en segundo lugar, y no dependiente del primero, contaminación del agua que podría ser aprovechada para consumo humano, factor, este último, que requiere atención en términos de las implicaciones sanitarias relacionadas, principalmente, a la ocurrencia de arsénico en ellas.

\subsection{ENTORNO GEOLÓGICO E HIDROGEOLÓGICO}

Los municipios de estudio se enmarcan dentro de la Región Hidrológica Administrativa número IV, conocida como "Balsas". Desde el punto de vista de conformación fisiográfica, la región se halla dividida por el cinturón volcánico TransMexicano, en su porción más septentrional y, en su porción sur, por la Sierra Madre del Sur, que corresponde a la mayor parte del área de estudio. Los rasgos morfológicos de la región están relacionados con esta última, específicamente con aquellos valles y sierras con altitudes medias y bajas (menores a los $2600 \mathrm{msnm}$ ). Los procesos geológicos determinados en ella establecen, sobre todo, la situación de los puntos considerados en esta investigación.

Desde el punto de vista geológico, Esteller et al. (2019) reconocen tres grupos principales y ofrecen una descripción más detallada de los mismos: (1) Rocas del pre-cretácico, que involucran dos unidades: esquisto Taxco y Roca Verde Taxco Viejo. Estas rocas forman parte de un complejo metamórfico (Pt y TRtv), constituido por una alternancia de metalavas, metatobas, metareniscas y metalutitas. Esta unidad es la más vieja de la zona de estudio y se considera el basamento sobre el cual la secuencia cretácica evolucionó; (2) Rocas del Cretácico: son parte de las formaciones Xochicalco (Kix) y Morelos (Kim). La primera se compone de una serie densa de calizas, finamente laminadas, de color oscuro, que alcanza, en promedio, los $150 \mathrm{~m}$. La segunda, por otra parte, consiste de calizas y dolomitas interestratificadas; y (3) Rocas del cenozoico, en las que se encuentran los siguientes afloramientos: (a) Granodiorita 
(a)

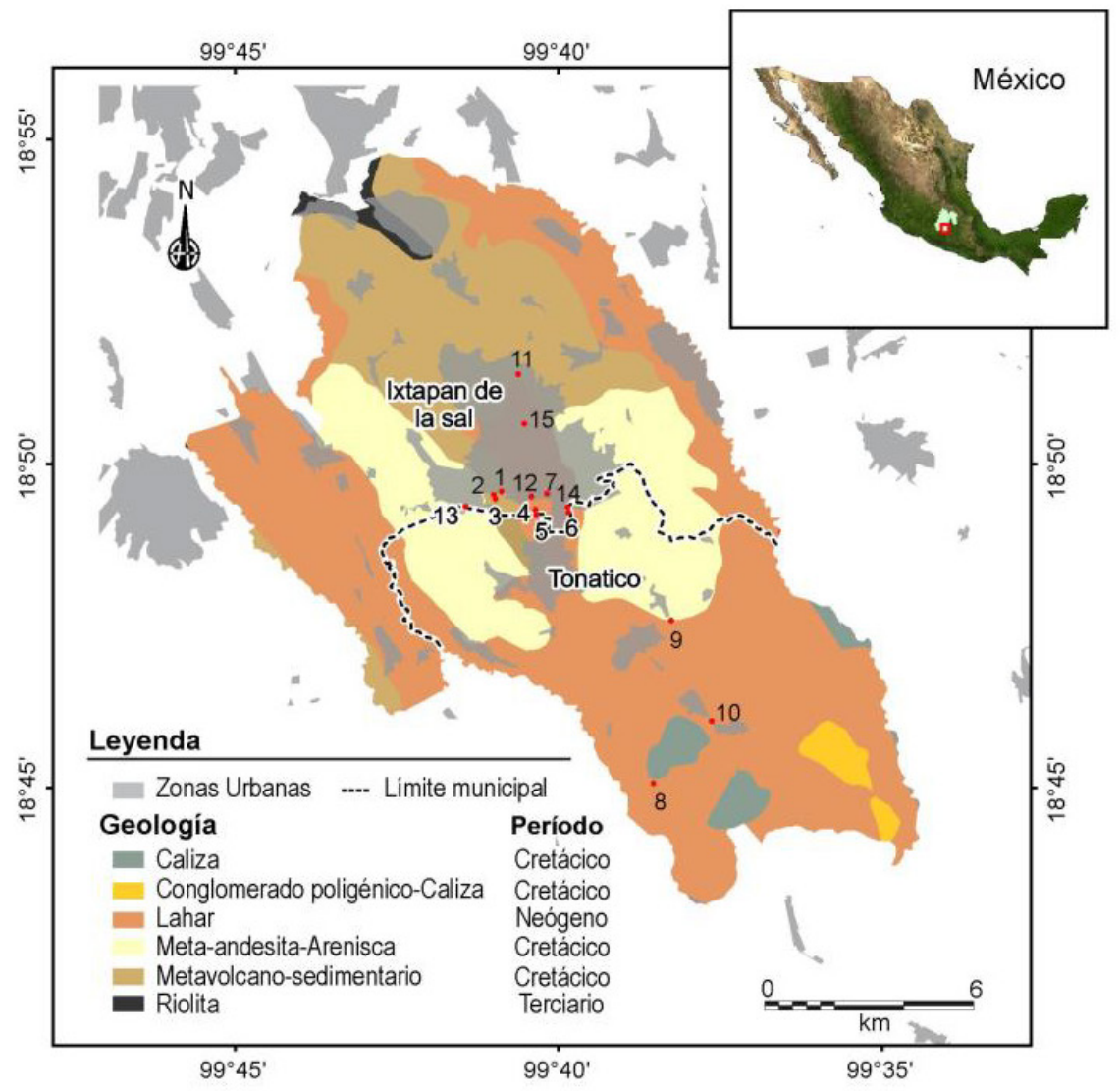

(b)

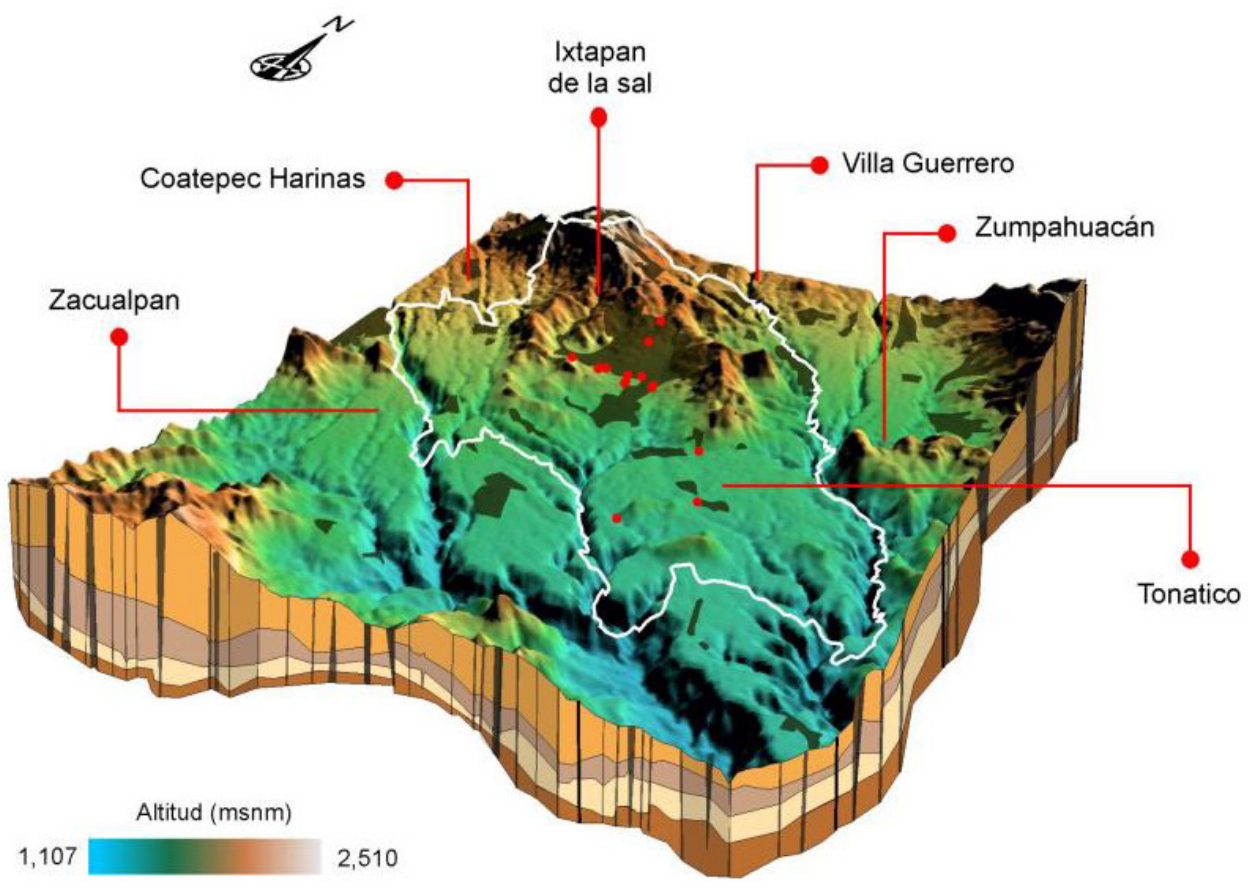

Figura 1 Localización general y regional de la zona de estudio en la que se contrasta la ubicación de los puntos de muestro para el año 2019 con: (a) la geología predominante y (b) La división administrativa municipal circundante y su conformación topográfica. 
(Ti), su afloramiento principal se halla a $7 \mathrm{~km}$ al oriente de la población de Tonatico, (b) Formación Chontalcoatlán (Tpch), que consiste en una secuencia de depósitos clásticos derivados de rocas del Sistema Volcánico Zinacantépetl, (c) Travertino (Qtr), formada por un paquete de rocas evaporíticas carbonatadas que afloran en la zona de estudio y (d) Aluvión, constituida por depósitos recientes derivados del intemperismo y erosión de las unidades más antiguas. Su granulometría es variable, pudiendo conformarse de gravas y arenas, así como de arcillas en otros lugares; en general, son materiales de espesores reducidos. La litología de la zona está caracterizada por la presencia de lahares (período neógeno), meta-andesita-arenisca (período cretácico) y metavolcano sedimentario (período cretácico), aunque existen otros tipos, pero de menor presencia en la misma (Figura 1).

Desde el punto de vista hidrogeológico, la zona de estudio se enmarca en el acuífero de Tenancingo. Este acuífero, en su porción inferior, que corresponde al área de estudio, alberga materiales granulares y rocas con poca y discontinua fractura y alta compacidad, que forman acuíferos de importancia mínima. En esta región Martínez-Florentino (2015) señala la existencia de dos unidades hidrogeológicas de importancia: (1) las secuencias volcánicas del Plio-Cuaternario, formadas por andesitas y basaltos, las cuales constituyen las principales unidades hidrogeológicas con capacidad para almacenar y transmitir importantes volúmenes de agua subterránea y (2) las calizas del cretácico de la Formación Morelos, que funcionan como zonas de transmisión de agua a otros materiales. Un tercer grupo, de menor importancia, estaría determinado por materiales granulares no consolidados de, relativamente, poco espesor, que generan horizontes saturados y acuíferos locales, como en el caso del municipio de Ixtapan de la Sal. Estos materiales impiden o limitan, en buena medida, la explotación del agua a través de pozos, siendo aprovechada ésta en manantiales que presentan variabilidad de caudal en función de, principalmente, las características de precipitación. Situación contraria presenta el municipio de Tonatico, con espesores mayores que permiten la explotación del agua en pozos someros.

Para la zona se distingue un flujo subterráneo preferencial de recarga con dirección Norte-Sur, proveniente, sobre todo, del Nevado de Toluca (Esteller et al., 2019). Regionalmente, dos sistemas de fallas se reconocen en la zona de estudio, la primera, con dirección NE-SO y, la segunda, NO-SE, la cual estaría determinando la circulación del agua en la región (Juan-Pérez, 1994). Tales fallas determinarían, de igual forma, el flujo de aguas termales que emerge en la zona de Ixtapan de la Sal, las cuales explican las condiciones de salinidad en ellas.

\section{Materiales y métodos}

\subsection{GARAGTERIZAGIÓN HIDROGEOQUÍMIGA}

\subsubsection{MUESTREO Y MÉTODOS ANALÍTICOS}

La caracterización hidrogeoquímica fue determinada, tanto espacial como temporalmente en la zona de estudio, con el análisis de dos conjuntos de datos: enero de 2015 (Martínez-Florentino, 2015) y abril de 2019 (determinados en esta investigación). Cuatro tipos de fuentes fueron considerados: manantiales termales, manantiales no termales, pozos y fuentes superficiales. Dos tipos de muestras fueron considerados: (1) muestras filtradas para aniones mayores, (2) muestras filtradas y acidificadas para cationes y Arsénico. Dichas muestras se conservaron en refrigeración a $4^{\circ} \mathrm{C}$.

La temperatura, el $\mathrm{pH}$, la conductividad eléctrica $(\mathrm{CE})$ y los sólidos disueltos totales (SDT), fueron determinados en campo con un equipo portátil Thermo Scientific Orion Star A329. La dureza total y la alcalinidad, con un equipo Digital Titrator modelo 16900, utilizando, como agentes titulantes, solución de EDTA y ácido sulfúrico, respectivamente. Los sulfatos y nitratos, en laboratorio, con metodología de colorimetría utilizando equipo 
portátil DR 850 y empleando como agente titulante Nitrato de Bario y Cadmio, respectivamente. Los cloruros se determinaron en laboratorio con nitrato de plata como agente de titulación. El arsénico total fue determinado por flama con generador de hidruros utilizando celda de cuarzo, con equipo Perkin Elmer AAnalyst 200, el cual tiene un límite de detección de $0.001 \mathrm{mg} / \mathrm{l}$. El control de calidad utilizado consistió en solución elemental de $100 \mathrm{mg} / \mathrm{l}$, Marca Environmental Express Cat\#QCS-27. El contenido de dióxido de carbono (denominado $E p C O_{2}$ ), relativo a una muestra de agua pura, fue calculado a partir de la Ecuación 1 (Neal et al., 1998):

$$
\operatorname{EpCO}_{2}=\left(A l k_{\mu E q / l}+10^{(6-p H)}-10^{(6-p H \text { endpoint })}\right) 10^{(6-p H)} / 6
$$

donde: $A l k_{\mu E q / \Omega}$ corresponde a la alcalinidad expresada en $\mu E q / l, \mathrm{pH}$ es la concentración de iones hidrógeno en el agua y $p H_{\text {endpoint }}$ el valor de $\mathrm{pH}$ del punto final de la determinación de la concentración de la alcalinidad, el cual usualmente es 4.3, por lo que la expresión $10^{(6-p H e n d p o i n t}$, equivale a 31.6 $\mu \mathrm{Eq} / \mathrm{l}$ (Jeong, 2001).

El error de electroneutralidad, para los iones mayores, fue calculado en las muestras como un indicador de la calidad de los análisis de hidroquímica realizados. Los errores se determinaron dentro del rango de $\pm 10 \%$, valor que coincide con el considerado adecuado por otros autores, tomando en cuenta los errores sistemáticos introducidos por las técnicas de titulación utilizadas en la investigación (Pacheco-Ávila et al., 2017).

\subsection{ANÁLISIS ESTADÍSTICO MULTIVARIADO}

El conjunto de determinaciones fisicoquímicas, de los años 2015 y 2019, fue utilizado como base para el análisis de componentes principales (ACP). Fueron incluidas aquellas variables que representan los elementos mayoritarios disueltos, así como algunos parámetros fisicoquímicos de interés correlacionados con los primeros, con lo que se consideró que podría tenerse una visión más amplia de los procesos geoquímicos que tienen lugar en la zona. Las variables seleccionadas para la realización del ACP fueron: temperatura, $\mathrm{pH}$, conductividad eléctrica, sólidos disueltos totales, $\mathrm{Ca}^{2+}, \mathrm{K}^{+}, \mathrm{Mg}^{2+}, \mathrm{Na}^{+}, \mathrm{Cl}, \mathrm{NO}_{3}^{-}, \mathrm{SO}_{4}^{2-}, \mathrm{HCO}_{3}^{-}, \mathrm{As} \mathrm{y}$ $\mathrm{EpCO}_{2}$.

Previo a la realización del ACP, los resultados analíticos fueron transformados logarítmicamente y, posteriormente, normalizados (z-scores), tanto para mitigar los efectos de las escalas de medida como para asegurar que parámetros altamente variables no dominaran el análisis (McLeod et al., 2017), logrando con ello que cada variable tuviera el mismo peso en el análisis estadístico. Para la normalización se utilizó la Ecuación 2:

$$
Z_{i}=\frac{X_{i}-\mu}{S},
$$

donde: $Z_{i}$ es la puntuación estándar de la muestra $i, X_{i}$, el valor de la muestra, $\mu$, la media y $S$ la desviación estándar.

El programa estadístico SPSS fue utilizado para llevar a cabo el ACP (Satyaji-Rao et al., 2010). Se adoptaron dos criterios para determinar el número de componentes principales $(\mathrm{CP})$ a seleccionar: (1) aquellos CP cuyos eigenvalores (valores propios) fueron mayores a la unidad y (2) el trazado y análisis del gráfico de sedimentación (Subyani y Al-Ahmadi, 2010). Asimismo, se utilizaron dos modos de extracción: (1) el modo R, que realiza la clasificación de acuerdo con la interacción entre las variables, y (2) el modo $Q$, que clasifica las muestras de acuerdo a sus parámetros, es decir, establece las relaciones existentes entre ellas, permitiendo el establecimiento de grupos con similitudes o, en el sentido contrario, disimilitudes fisicoquímicas. Para facilitar la interpretación de los factores seleccionados se recurrió a la rotación ortogonal de los ejes factoriales a través del método Varimax con la normalización Kaiser (Subyani y Al-Ahmadi, 2010). En este sentido, la explicación del fenómeno en estudio sigue un orden descendente, en la medida que, el primer CP, explica el máximo de la varianza de los procesos en el área de estudio, mientras que el segundo factor y los subsecuentes explican el máximo de la varianza común restante, en magnitudes (varianzas) cada vez menores. 


\subsection{GEOESTADÍSTICA PARA EL MAPEO DE LA GALIDAD DE AGUA}

\subsubsection{ANÁLISIS ESTRUCTURAL DE LOS DATOS: ANÁLISIS VARIOGRÁFICO}

La geoestadística se basa en el análisis de la continuidad espacial y la variación temporal de las variables hidroquímicas, y tiene su fundamento en el cálculo del variograma experimental y teórico (análisis variográfico). Su base matemática se deriva de la Ecuación 3.

$\gamma(h)=\frac{1}{2 n} \sum_{i=1}^{n}\left[Z\left(x_{i}\right)-Z\left(x_{i}+h\right)\right]^{2}$,

donde: $n$ es el número de pares o puntos de muestreo separados por una distancia estándar denominada $h, \mathrm{Z}\left(x_{i}\right)$, el valor de la variable $\mathrm{z}$ en la localidad $x_{i}$, los cuales tienen valores medidos en la variable regionalizada $\mathrm{Z}(x)$ y $x_{i}$, un punto de muestreo con $i=1 \ldots n$ (Webster y Oliver, 2014).

A diferencia del enfoque adoptado por otros autores (Sánchez-Martos et al., 2001), quienes utilizaron el modelo de variograma esférico sin un análisis estadístico previo de adecuación, esta investigación realizó un análisis variográfico, basado en la validación cruzada, para la selección del modelo de ajuste más adecuado para llevar a cabo la interpolación de las variables. Para ello se seleccionaron cinco índices de ajuste: el error máximo (ME), raíz cuadrada media del error (RMSE), coeficiente de determinación (CD), eficiencia del modelo $(\mathrm{EF})$ y el coeficiente de masa residual (CRM). Sus expresiones matemáticas están descritas en literatura relacionada (Homaee et al., 2002). Los valores esperados en un ajuste perfecto son los siguientes: $\mathrm{ME}=0, \mathrm{RMSE}=0$, $\mathrm{CD}=1, \mathrm{EF}=1$ y $\mathrm{CRM}=0$.

\subsubsection{INTERPOLACIÓN DE LAS VARIABLES: KRIGING ORDINARIO}

Una vez realizado el análisis variográfico, es posible realizar la interpolación de las variables de interés considerando la Ecuación 4, en la que se fundamenta la técnica de kriging ordinario.

$$
\hat{z}\left(x_{0}\right)=\sum_{i=1}^{n} \lambda_{i} z\left(x_{i}\right),
$$

donde: $\quad \hat{z}$ es el valor estimado de un atributo en un punto de interés $x_{0}$, $z$, el valor observado en el punto muestreado $x_{i}, \lambda_{i}$, el peso asignado al punto de muestreo y $n$ representa el número de puntos muestreados usados para la estimación (Webster y Oliver, 2014).

El kriging ordinario ha sido de los más ampliamente utilizados (Gorai y Kumar, 2013). En tal sentido, Ebrahimi et al. (2011) compararon 8 métodos para interpolar la variable sodio en Kohpayeh-Segzi, Irán, para un total de 36 muestras de agua subterránea utilizada para consumo. Sus resultados muestran que, dentro de todas las metodologías de interpolación evaluadas, el kriging ordinario ofreció los mejores resultados con el menor valor del índice de ajuste RMSE.

La presente investigación, en contraposición a otros autores (Nas y Berktay, 2010; Gorai y Kumar, 2013), quienes realizaron la interpolación individual de variables fisicoquímicas específicas de interés, se inclinó hacia la metodología desarrollada por Sánchez-Martos et al. (2001) y McLeod et al. (2017), quienes optaron por la interpolación de las puntuaciones factoriales en sus zonas de estudio (resultantes de la aplicación del modo Q del ACP). El enfoque metodológico, retomado por estos últimos, posee algunas características que lo hacen particularmente atractivo para los intereses de esta investigación: (1) la superficie de predicción lograda lleva implícito el conjunto de parámetros fisicoquímicos que, en él (el componente principal), están involucrados, llevando a generalizar la influencia inherente que éstos conllevan en el agua de la zona de estudio y (2) se posibilita el análisis en un espacio ortogonal multivariado (las variables son linealmente independientes), el cual es más reducido que al realizar el análisis con las variables originalmente establecidas en la investigación.

Se utilizó el programa feostat para la realización del análisis variográfico, así como para la realización del kriging ordinario de las variables, y el programa Arcgis 10.4, para la generación de las superficies de predicción de las variables en función de los resultados obtenidos con el primero. $\mathrm{Su}$ principio de funcionamiento, al igual que el pro- 
ceso de generación de los archivos derivados de su implementación, son descritos en la literatura relacionada (Ali-Mert y Dag, 2017).

\section{Resultados y discusión}

\subsection{ANÁLISIS DE LA GARAGTERIZAGIÓN HIDROQUÍMICA}

Las Figuras $2 a$ y $2 b$ muestran la composición química del agua en función del tipo de fuente muestreada: (1) manantiales termales, (2) manantiales no termales, (3) pozos y (4) fuentes superficiales. En tal sentido, para ambos períodos de muestreo, tres grupos químicos se identifican en las muestras. Para el realizado hacia el año 2019, los sitios de muestreo se distribuyen, en ellos, de la siguiente manera: tipo $\mathrm{Ca}^{2+} \mathrm{HCO}_{3}{ }^{-}$(puntos 8, 9, 10, 13 y 14, Tabla 1), $\mathrm{Ca}^{2+}-\mathrm{Mg}^{2+}-\mathrm{Cl}$ (puntos 1, 2, 4 y 12) y $\mathrm{Na}^{+}$- $\mathrm{Cl}^{-}$(puntos $3,5,6,7,11$ y 15). El segundo grupo corresponde a sitios considerados no termales pero que poseen, en concordancia con los resultados obtenidos por Esteller et al. (2019), características intermedias entre los pozos (tipo $\mathrm{Ca}^{2+}-\mathrm{HCO}_{3}^{-}$) y las aguas termales (tipo $\mathrm{Na}^{+}-\mathrm{Cl}$ ).
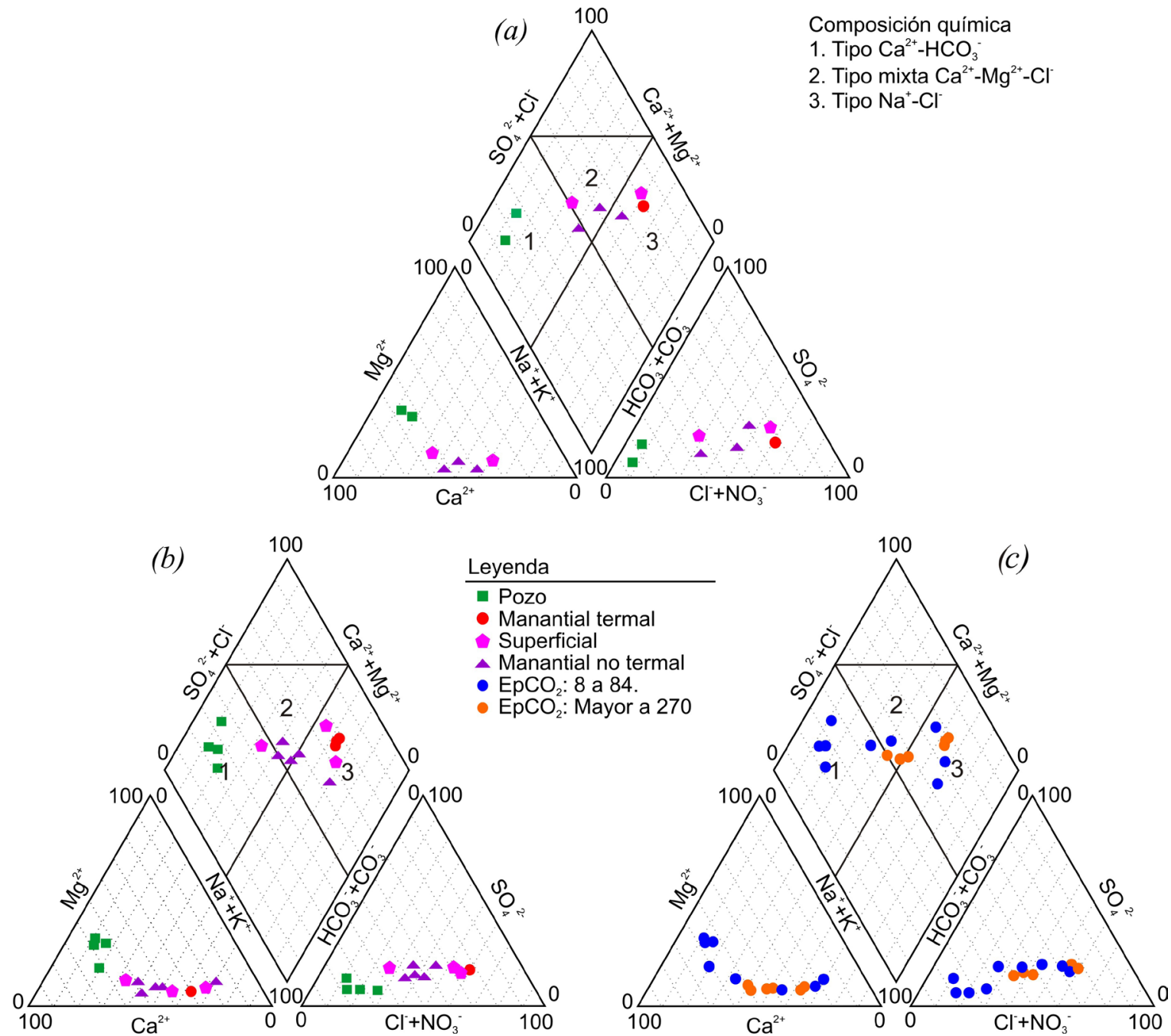

Figura 2 Diagrama de Piper mostrando la composición química de las muestras de agua para los dos períodos de muestreo establecidos en la zona de estudio: (a) 2015 y (b) 2019, (c) el diagrama que muestra la relación entre el $E p C O_{2}$ y la composición química del agua para el año 2019. 
Al revisar el parámetro SDT (Tabla 1), para los tres grupos químicos determinados (Figura 2b), en promedio, éste se cuantifica, respectivamente, en $303.5 \mathrm{mg} / \mathrm{l}$ (tipo $\mathrm{Ca}^{2+}{ }_{-} \mathrm{HCO}_{3}$ ) $), 797.97 \mathrm{mg} / \mathrm{l}$ (tipo $\mathrm{Ca}^{2+}-\mathrm{Mg}^{2+}-\mathrm{Cl}$ ) y $3214.68 \mathrm{mg} / \mathrm{l}\left(\right.$ tipo $\mathrm{Na}^{+}-\mathrm{Cl}^{-}$), clasificando las aguas como dulces $(<1000 \mathrm{mg} / \mathrm{l}$ en SDT) y salobres (>1000 mg/l en SDT). De entre estos tres tipos, las muestras de aguas termales, todas ubicadas dentro del tipo $\mathrm{Na}^{+}$- $\mathrm{Cl}$, son las que presentan las mayores concentraciones de SDT (Tabla 1).

Las concentraciones catiónicas y aniónicas predominantes en la zona están determinadas de la siguiente manera: $\mathrm{Na}^{+}>\mathrm{Ca}^{2+}>\mathrm{K}^{+}>\mathrm{Mg}^{2+}$, de las cuales, los primeros dos elementos representan el $58.32 \%$ y $30.94 \%$ de los cationes, respectivamente, mientras que en los aniones existe una relación descendente de $\mathrm{HCO}_{3}{ }^{-}>\mathrm{Cl}->\mathrm{SO}_{4}{ }^{2-}>\mathrm{NO}_{3}$, donde los dos primeros representan el $40.27 \%$ y $40.05 \%$ de los mismos. En términos generales, las características del agua indican una naturaleza dura: 10 muestras de naturaleza muy dura $>300$ $\mathrm{mg} / \mathrm{L} \mathrm{CaCO}_{3}$ ) contra 5 de tipo duro (entre $150 \mathrm{a}$ $300 \mathrm{mg} / \mathrm{L} \mathrm{CaCO}_{3}$ ).

Un amplio rango de las concentraciones de sulfatos caracteriza las muestras analizadas en el área de estudio (15.2-956.7 mg/l). El promedio $(92.2 \mathrm{mg} / \mathrm{l})$ de las fuentes con potencialidad de uso para consumo humano (pozos y manantiales no termales) no supera el límite máximo permisible de $250 \mathrm{mg} / \mathrm{l}$ de sulfatos (WHO, 2011). Para este parámetro pueden ser clasificados tres rangos en las muestras: menores a $74.5 \mathrm{mg} / \mathrm{l}$, entre $92.2 \mathrm{y}$ $290.5 \mathrm{mg} / \mathrm{l}$ y mayores a $872.5 \mathrm{mg} / \mathrm{l}$. Las muestras provenientes de los pozos se clasifican dentro del primer grupo. En el segundo grupo se ubican todos los manantiales no termales y dos fuentes superficiales, mientras que el rango más alto corresponde a las fuentes termales. Las concentraciones de bicarbonatos varían entre 248 y 1543.03 $\mathrm{mg} / \mathrm{l}$, mientras que el $\mathrm{pH}$ oscila desde 6.1 hasta 7.9. Las aguas con alto contenido de sulfatos se caracterizan por altos contenidos de bicarbonatos y, en términos generales, puede inferirse un origen común de ambos elementos por su alto nivel de correlación $\left(\mathrm{R}^{2}=0.982\right)$.
Adicionalmente, y considerando que éste es un acuífero carbonatado, la disolución de dolomita y de calcita se consideran procesos importantes. En ese sentido, los sitios de muestreo con contenidos medios y altos de sulfatos presentarían mayores tasas de disolución de calcita tomando en cuenta la relación molar $\mathrm{Mg}^{2+} / \mathrm{Ca}^{2+}$, que, en promedio, corresponden a 0.18 y 0.23 , respectivamente. Por el lado contrario, un incremento en dicha relación molar (0.51) indicaría, para las aguas con menores niveles de sulfato, una mayor disolución de dolomita, posiblemente causado por un mayor tiempo de residencia y, en consecuencia, una mayor interacción agua-roca (Garfias et al., 2010). Esta disolución de dolomita es un proceso relevante en la zona de estudio, en la que existe una correlación directa entre el contenido de sulfatos y calcio (Figura $3 g$ ). En la zona se infieren procesos de dedolomitización, en los que se generan incrementos de calcio, magnesio y contenido de $\mathrm{EpCO}_{2}$ y un descenso en la alcalinidad y el pH. Los resultados obtenidos en esta investigación coinciden con los reportados por Cardenal et al. (1994), quienes establecen que este proceso (dedolomitización) es importante en su zona de estudio cuando el yeso o la anhidrita están presentes, situación que ha sido demostrada en los resultados aquí obtenidos (Figura $3 g$ ). En ese sentido, señalan, la reacción neta que involucra este proceso está definida por la reacción química 5, en la que "el proceso continúa con la disolución simultánea de yeso (o anhidrita) y dolomita, junto con la precipitación de la calcita".

$$
\mathrm{CaMg}\left(\mathrm{CO}_{3}\right)_{2}+\mathrm{CaSO}_{4} \rightarrow 2 \mathrm{CaCO}_{3}+\mathrm{MgSO}_{4(a c)}
$$

\subsection{ANÁLISIS HIDROQUíMICO}

Tomando en consideración que uno de los objetivos de esta investigación consistió en establecer el origen para algunos de los elementos químicos predominantes en el agua de la zona de estudio, se razonó necesario realizar la evaluación de las relaciones existentes entre las concentraciones de iones mayoritarios. Es por esto que la utilización de relaciones hidroquímicas que identifiquen procesos de disolución específicos se introdujo a partir 
Tabla 1. Composición fisicoquímica del agua de la región de estudio para el período de muestreo del año 2019. La ubicación física de cada sitio de muestreo se presenta en la Figura 1.

\begin{tabular}{|c|c|c|c|c|c|c|c|c|c|c|c|c|c|c|c|c|c|c|c|c|c|}
\hline 집 & $\begin{array}{l}8 \\
i \\
i \\
10\end{array}$ & 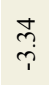 & 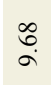 & $\begin{array}{l}8 \\
i \\
1\end{array}$ & $\stackrel{\stackrel{i}{i}}{\text { s. }}$ & $\hat{\infty}$ & $\begin{array}{l}\stackrel{0}{i} \\
\stackrel{i}{i}\end{array}$ & $\stackrel{?}{2}$ & & m. & $\stackrel{\widetilde{F}}{\sigma}$ & $\stackrel{m}{\rightarrow}$ & $\stackrel{\partial}{\vec{\gamma}}$ & 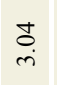 & $\stackrel{⿱ 亠 䒑}{\vec{r}}$ & $\stackrel{2}{\hdashline}$ & & ' & & & ' \\
\hline . & 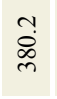 & & 过 & $\overrightarrow{\mathrm{I}}$ & त̊. & $\stackrel{\hat{\sigma}}{\hat{\sigma}}$ & $\frac{n}{\vec{J}}$ & I & & ले & in & 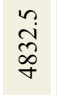 & $\vec{\phi}$ & $\ddot{6}$ & $\begin{array}{l}\infty \\
\stackrel{\infty}{\infty} \\
-\end{array}$ & $\frac{\partial}{\vec{d}}$ & $\overline{\mathrm{I}}$ & $\begin{array}{c}n \\
\tilde{3} \\
\stackrel{\infty}{\sigma}\end{array}$ & 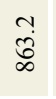 & 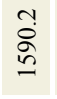 & 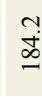 \\
\hline 歇。 & in & 嵒 & if & ô & 帒 & $\stackrel{\text { సे }}{\infty}$ & î & 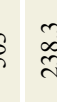 & & ্ָয & 总 & $\begin{array}{l}\infty \\
\stackrel{0}{0} \\
\stackrel{0}{\infty}\end{array}$ & 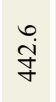 & ָ̃ & $\frac{a}{m}$ & $\begin{array}{l}\vec{j} \\
\stackrel{n}{a}\end{array}$ & $\stackrel{8}{0}$ & $\begin{array}{l}\dot{a} \\
\dot{n} \\
\sigma\end{array}$ & $\begin{array}{l}n \\
\tilde{n} \\
i n\end{array}$ & हn & $\stackrel{\hat{\alpha}}{\alpha}$ \\
\hline 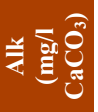 & 号 & đั & $\widetilde{\vartheta}$ & $\frac{N}{m}$ & in & d & $\stackrel{8}{\beth}$ & ק్ & & 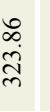 & 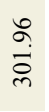 & $\begin{array}{l}\tilde{\text { İ }} \\
\stackrel{\Xi}{\Xi}\end{array}$ & $\begin{array}{l}\underset{7}{ \pm} \\
\underset{n}{n}\end{array}$ & $\begin{array}{l}\stackrel{8}{\circ} \\
\tilde{n}\end{array}$ & $\begin{array}{l}\infty \\
\infty \\
i \\
\tilde{n}\end{array}$ & 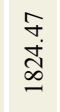 & 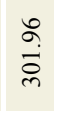 & 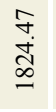 & స్రి & 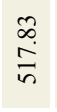 & $\underset{\infty}{\mathbb{1}}$ \\
\hline ₹奇 & ? & ஸิ & $\stackrel{t}{0}$ & $\tilde{3}$ & $\tilde{c}$ & 3 & $\stackrel{\bullet}{\circ}$ & a & & $\vec{\circ}$ & ¿. & $\stackrel{t}{\stackrel{t}{0}}$ & $\bar{m}$ & $\overrightarrow{0}$ & $\stackrel{\overbrace{}}{0}$ & I & $\overrightarrow{0}$ & $I$ & గొర & $\stackrel{\text { fo }}{\circ}$ & )े \\
\hline 8 & $\begin{array}{l}\vec{b} \\
\text { in }\end{array}$ & $\frac{n}{2}$ & 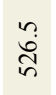 & 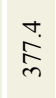 & 㝎 & $\tilde{n}$ & 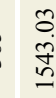 & $\stackrel{\infty}{\infty}$ & & 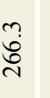 & $\stackrel{\infty}{d}$ & $\stackrel{0}{\infty}$ & वे. & ते & ๙ิ & $\begin{array}{c}\tilde{a} \\
\stackrel{a}{g}\end{array}$ & $\stackrel{\infty}{\sim}$ & 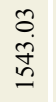 & $\overline{\text { gे }}$ & $\overrightarrow{\tilde{g}}$ & $\vec{b}$ \\
\hline 总 & $\stackrel{\infty}{ \pm}$ & 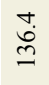 & $\begin{array}{l}\text { 迥 } \\
\text { in }\end{array}$ & $\stackrel{m}{\Xi}$ & ñ & $\begin{array}{l}n \\
\tilde{n} \\
n\end{array}$ & ڤ్ & 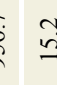 & & $\stackrel{\vec{n}}{\ddot{n}}$ & તે & $\underset{\substack{n \\
\infty}}{\stackrel{n}{i}}$ & ָี่ & $\stackrel{\substack{\infty \\
\infty}}{\infty}$ & $\stackrel{n}{i}$ & $\overrightarrow{\stackrel{\rho}{\infty}}$ & กี & 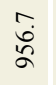 & $\overrightarrow{\vec{N}}$ & \begin{tabular}{l}
\multirow{\sigma}{0}{} \\
లై
\end{tabular} & $\overline{\mathrm{I}}$ \\
\hline & in & $\stackrel{3}{9}$ & $\tilde{m}$ & $\begin{array}{l}n \\
\infty\end{array}$ & îj & N & $\stackrel{\sim}{m}$ & $\frac{1}{4}$ & & $n$ & $\infty$ & $\stackrel{\Xi}{\leftrightarrows}$ & $\stackrel{\dot{m}}{m}$ & $\stackrel{\beth}{\beth}$ & $\hat{b}$ & $\stackrel{+}{\Xi}$ & $\stackrel{m}{3}$ & $\frac{\stackrel{3}{m}}{m}$ & 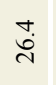 & $\underset{m}{\stackrel{m}{m}}$ & 竎 \\
\hline ర大 & त్ & $\hat{n}$ & हે & $\stackrel{ \pm}{\Xi}$ & ڤે & 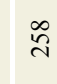 & ָิ & $\bar{\lambda}$ & & $\widehat{\underline{I}}$ & $\stackrel{\vec{g}}{g}$ & तें & $\begin{array}{l}\text { bे } \\
\stackrel{n}{n}\end{array}$ & $\hat{n}$ & $\stackrel{n}{\infty}$ & $\begin{array}{l}\text { בे } \\
\overline{\text { ते }}\end{array}$ & 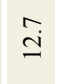 & $\begin{array}{l}\text { ָे } \\
\text { নิ }\end{array}$ & हे & స్రై & $\stackrel{\infty}{=}$ \\
\hline & 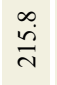 & $\overrightarrow{\dot{\infty}}$ & 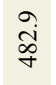 & $\widehat{\grave{I}}$ & in & $\stackrel{\infty}{\stackrel{\tilde{N}}{0}}$ & 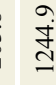 & ì & & $\bar{\sim}$ & $\bar{\Xi}$ & $\underset{\substack{m \\
\infty \\
\infty}}{\infty}$ & $\begin{array}{l}m \\
\infty \\
m\end{array}$ & $\begin{array}{l}\infty \\
\stackrel{\infty}{\infty}\end{array}$ & $\hat{\sigma}$ & $\begin{array}{l}\stackrel{D}{\infty} \\
\vec{\Xi}\end{array}$ & $\stackrel{\infty}{\stackrel{\infty}{=}}$ & $\begin{array}{l}\vec{D} \\
\stackrel{\infty}{\vec{\Xi}}\end{array}$ & $\stackrel{m}{\stackrel{q}{q}}$ & $\begin{array}{l}\infty \\
\stackrel{\infty}{i} \\
i n\end{array}$ & $\stackrel{7}{\unlhd}$ \\
\hline & $\stackrel{\circ}{\stackrel{\circ}{\leftrightarrows}}$ & $\begin{array}{l}\infty \\
\text { in }\end{array}$ & $\begin{array}{l}\infty \\
\stackrel{m}{m}\end{array}$ & $\vec{m}$ & $\begin{array}{l}\stackrel{b}{0} \\
\dot{m}\end{array}$ & $\stackrel{0}{2}$ & 率 & $\exists$ & & 齐 & चे & $\begin{array}{l}3 \\
\infty \\
\infty\end{array}$ & 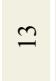 & $\stackrel{\Xi}{\sim}$ & $\underset{\ddot{n}}{\ddot{n}}$ & $\begin{array}{l}\stackrel{a}{\infty} \\
\infty\end{array}$ & $\cong$ & గn & 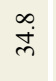 & $\overrightarrow{\mathrm{i}}$ & $\stackrel{\infty}{\infty}$ \\
\hline 达昌 & $\overrightarrow{\vec{\lambda}}$ & $\stackrel{+}{\Xi}$ & $\stackrel{n}{\text { mे }}$ & $\stackrel{\dot{\oplus}}{\mathrm{g}}$ & $\stackrel{\circ}{\circ}$ & ते & $\stackrel{m}{=}$ & 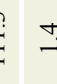 & & $\stackrel{\infty}{-}$ & $\stackrel{\Xi}{-}$ & $\stackrel{n}{g}$ & $\underset{\sim}{\tilde{i}}$ & $\stackrel{9}{-}$ & $\stackrel{\sim}{=}$ & $\vec{\infty}$ & $\stackrel{ \pm}{-}$ & $\stackrel{n}{ \pm}$ & 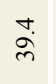 & $\begin{array}{l}\stackrel{\circ}{\dot{q}} \\
\ddot{q}\end{array}$ & ปे \\
\hline & ڤે & $\stackrel{\infty}{\stackrel{\infty}{n}}$ & 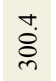 & 灾 & in & $\stackrel{\vec{\gamma}}{\dot{\gamma}}$ & gे & $\approx$ & & ñ & $\therefore$ & in & ڤై & 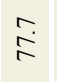 & $\bar{\Xi}$ & $\frac{\infty}{6}$ & $\stackrel{\vec{f}}{\vec{f}}$ & $\stackrel{\infty}{6}$ & $\stackrel{\vec{N}}{\sim}$ & $\stackrel{\ddot{\alpha}}{\alpha}$ & $\frac{m}{a}$ \\
\hline 悹劎 & 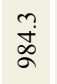 & $\underset{\infty}{\stackrel{+}{\vec{D}}}$ & $\widehat{్ ర క}$ & $\begin{array}{l}\hat{b} \\
\text { బె }\end{array}$ & $\stackrel{\check{\varrho}}{\Xi}$ & $\begin{array}{l}n \\
\stackrel{n}{\alpha}\end{array}$ & \begin{tabular}{l}
\multirow{2}{n}{} \\
\multirow{2}{\gamma}{}
\end{tabular} & ลิ & & ষ্ల & $\underset{\sim}{\tilde{N}}$ & $\begin{array}{l}\text { m. } \\
\text { } \\
\stackrel{\sigma}{\sigma}\end{array}$ & $\stackrel{m}{\tilde{\sigma}}$ & $\underset{\sim}{\stackrel{\sim}{\sim}}$ & 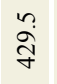 & 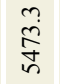 & $\underset{\pi}{\pi}$ & $\underset{\substack{m \\
\tilde{H}}}{\tilde{F}}$ & $\begin{array}{l}\stackrel{\infty}{0} \\
\stackrel{2}{n}\end{array}$ & 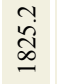 & 导 \\
\hline 동 & 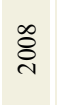 & 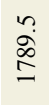 & ల్లె & ָ̃ & :̊ & $\stackrel{n}{\stackrel{n}{\infty}}$ & $\frac{1}{n}$ & $\begin{array}{l}4 \\
\text { nin }\end{array}$ & & 柋 & $\stackrel{\infty}{+}$ & $\begin{array}{l}\stackrel{m}{\vec{U}} \\
\stackrel{\Xi}{0}\end{array}$ & $\stackrel{\overrightarrow{\tilde{D}}}{\stackrel{\oplus}{n}}$ & $\hat{n}$ & શે & $\stackrel{8}{\Xi}$ & $\stackrel{\&}{\stackrel{8}{+}}$ & $\stackrel{8}{\Xi}$ & 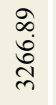 & 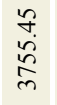 & $\begin{array}{l}\stackrel{\leftrightarrow}{g} \\
\stackrel{J}{=}\end{array}$ \\
\hline $\bar{z}$ & రొ & ? & $\stackrel{n}{n}$ & $\stackrel{2}{2}$ & $\stackrel{i}{\therefore}$ & $\stackrel{?}{\simeq}$ & ชู & 3 & & 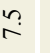 & $\stackrel{?}{r}$ & $\overrightarrow{6}$ & రి. & $\stackrel{?}{r}$ & $\stackrel{\infty}{\sim}$ & ชู & $\overrightarrow{6}$ & $\stackrel{2}{r}$ & $\stackrel{\text { ㅇ․ }}{ }$ & $\stackrel{\circ}{0}$ & $\hat{\infty}$ \\
\hline$\stackrel{0}{\circ}$ & $\tilde{\tilde{\nu}}$ & $\stackrel{a}{\vec{d}}$ & הี & $\overline{\mathrm{i}}$ & $\overline{\tilde{n}}$ & $\stackrel{\infty}{\tilde{\lambda}}$ & $\begin{array}{l}\text { ले } \\
\text { m. }\end{array}$ & $\stackrel{i}{i}$ & & mat & ָై & $\stackrel{m}{\sim}$ & $\stackrel{\infty}{\underset{\sim}{j}}$ & 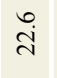 & $\stackrel{n}{\simeq}$ & ڤn & $\stackrel{n}{I}$ & in & $\stackrel{\infty}{\stackrel{\infty}{\sim}}$ & $\stackrel{?}{\sim}$ & $\stackrel{+}{\stackrel{2}{I}}$ \\
\hline 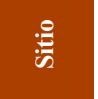 & $\vec{z}$ & $\sum_{\Sigma}^{\tilde{z}}$ & $\vec{n}$ & $\hat{Z}_{\Sigma}^{\tilde{Z}}$ & $\tilde{\omega}$ & $\stackrel{+}{\xi}$ & $\bar{E}$ & $\bar{a}$ & & $\approx$ & $\bumpeq$ & $\vec{E}$ & $\stackrel{n}{z}$ & $\stackrel{ \pm}{a}$ & $\tilde{n}$ & $\stackrel{\tilde{E}}{\Sigma}$ & \multirow{2}{*}{ 悬 } & \multirow{2}{*}{\multicolumn{2}{|c|}{ 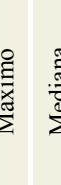 }} & \multirow{2}{*}{$\hat{\theta}$} & \multirow{2}{*}{3} \\
\hline 音 & - & $N$ & $m$ & $\sigma$ & in & 6 & $r$ & $\infty$ & & $a$ & 으 & $=$ & $\simeq$ & $\stackrel{2}{2}$ & \pm & 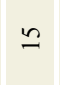 & & & & & \\
\hline
\end{tabular}


de experiencias previas (Ma et al., 2014), logrando con ello una aproximación hacia los principales procesos que controlan la evolución química del agua y que han sido señalados en las etapas anteriores. La Figura 3 muestra las relaciones establecidas.

\subsubsection{INFLUENGIA DE LAS SALES DE GLORURO}

La gráfica de iones mayoritarios fue utilizada para establecer algunas conclusiones respecto de la composición química del agua en la zona de estudio. Así se espera una relación 1:1 entre los cationes mayoritarios $\left(\mathrm{Ca}^{2+}+\mathrm{Mg}^{2+}+\mathrm{Na}^{+}+K^{+}\right)$y el ion cloruro, estimando la disolución de las sales de cloruros (Ma et al., 2014). En la Figura $3 a$ puede apreciarse que todos los puntos se dispersan ampliamente de la equilínea, lo que indica que la disolución de sales de cloruro no es la fuente mayor de los cationes totales. Tal desviación podría estar asociada a otros procesos, como la disolución de minerales de silicatos y carbonatados, o ser consecuencia del intercambio iónico.

\subsubsection{DISOLUCIÓN DE MINERALES DE SILICATO E INTERCAMBIO IÓNICO}

La relación mostrada en la Figura $3 b$ permite introducir la posible disolución de silicatos o los procesos de intercambio iónico en la zona de estudio. Si dichos procesos son significativos en la composición química del agua, la relación entre ambos parámetros utilizados $\left(\left(\mathrm{Ca}^{2+}+\mathrm{Mg}^{2+}\right)-\left(\mathrm{HCO}_{3}{ }^{-}+\mathrm{SO}_{4}^{2-}\right)\right.$ y $\left.\left(\mathrm{Na}^{+}+K^{+}\right)-\mathrm{Cl}\right)$ debería de ser lineal y con una pendiente negativa equivalente a -1 (Jalali, 2005; Kim et al., 2004). En la Figura $3 b$ puede apreciarse que un $66 \%$ de las muestras se ubica alrededor de la equilínea mostrada, implicando que, al menos para ellas, los procesos de disolución de silicatos y el intercambio iónico podrían ser significativos en su composición química.

\subsubsection{ORIGEN DEL SODIO}

La relación entre sodio y cloruros ha sido utilizada para identificar los mecanismos de adquisición de salinidad. La Figura $3 c$, que relaciona estos elementos, muestra que el $100 \%$ de las muestras se ubica alrededor o sobre la equilínea 1:1, pues un incremento de sodio va asociado a uno de cloruros $\left(\mathbf{R}^{2}=0.9937\right)$, por lo que puede inferirse que existe un probable proceso de meteorización de las rocas (Meybeck, 1987). Esta alta correlación podría indicar, adicionalmente, la disolución de halita en el medio, puesto que ésta aporta concentraciones iguales de sodio y cloruros, considerándose así que estos elementos tienen su origen en el mismo proceso.

Es conveniente, en este punto, introducir otro aspecto que vincularía el origen del sodio con la disolución de silicatos antes revisada. La relación molar $\mathrm{Na}^{+} / \mathrm{Cl}$ está vinculada con la liberación de sodio a partir de la disolución de minerales de silicato. En ese sentido, puede afirmarse que este proceso tiene importancia para el aporte de este elemento en la zona, puesto que un $73 \%$ de los sitios presenta una relación superior a uno. Un aporte adicional de sodio estaría relacionado con la disolución de minerales de sulfato de magnesio, esto al considerar la alta correlación existente entre sodio y sulfato $\left(\mathrm{R}^{2}=0.9799\right)$, lo que podría indicar una fuente común de origen hacia el medio acuífero.

\subsubsection{ORIGEN DEL CALCIO Y MAGNESIO}

Jalali (2005) sugiere que si los elementos calcio, magnesio, sulfatos y bicarbonatos proceden de la disolución simple de calcita, dolomita y yeso, debería conducir a un balance de carga entre estos cationes y aniones. La Figura $3 d$ muestra la relación existente entre tales elementos. Puede apreciarse que un 53\% (8 puntos) se halla alrededor y sobre la equilínea, indicando la participación de la disolución de minerales de carbonato y sulfato en la hidroquímica, mientras que 7 sitios se hallan por debajo de ella, indicando la disolución de silicatos y el intercambio iónico, determinados previamente en la Figura $3 b$. Desde este punto de vista, la Figura $3 d$ determinaría que las concentraciones de calcio y magnesio, de ese $53 \%$ de las muestras, son afectadas por la disolución de minerales carbonatados, como la calcita y la dolomita. La Figura $3 e$, que relaciona $\mathrm{Ca}^{2+}+M \mathrm{~g}^{2+}$ en función de $\mathrm{HCO}_{3}^{-}$, fue utilizada para profundizar en la participación de la disolución de dolomita sobre 
la concentración de los primeros dos elementos. Puede apreciarse que, para un $73 \%$ de las muestras, la disolución de este mineral es de importancia pues ellas se ubican alrededor de la equilínea.

De forma complementaria, el intercambio iónico, como fue descrito anteriormente, podría estar teniendo participación en el incremento en la concentración de sodio de algunas muestras, en las que este elemento podría intercambiarse con el calcio y magnesio adsorbido en las superficies de los minerales, dando como resultado una reducción de la concentración de estos últimos y un aumento del primero. Ello se expresaría en la relación existente de concentraciones catiónicas promedio para la zona: $\mathrm{Na}^{+}>\mathrm{Ca}^{2+}>K^{+}>\mathrm{Mg}^{2+}$ (Tabla 1).

Para complementar, la Figura $3 f$ muestra que existe una alta correlación entre el $\mathrm{Ca}^{2+}$ y $\mathrm{HCO}_{3}$ $\left(\mathrm{R}^{2}=0.9291\right)$, indicando que una fuente adicional importante de calcio en la zona podría estar conformada por la disolución de la calcita. Por otro lado, existe una alta correlación entre sulfatos y calcio $\left(\mathrm{R}^{2}=0.9225\right)$, con lo que se puede inferir la existencia de procesos de disolución evaporítica. La Figura $3 g$ es utilizada para determinar la participación de la disolución de yeso en el aporte de calcio. Puede apreciarse que sólo tres sitios $(20 \%)$ se hallan alrededor de la equilínea, lo cual indica que el yeso no es una fuente importante de calcio en la zona, pudiendo así derivarse éste de la disolución de otro mineral evaporítico tal como la anhidrita.

La Figura $3 h$, que relaciona el magnesio en función de los bicarbonatos, muestra que pueden existir otras fuentes de magnesio en la zona, ya que el 100\% de los puntos se aleja de la equilínea. Todavía cabe señalar que otra fuente adicional de magnesio podría estar constituida por la disolución de minerales de sulfato de magnesio, puesto que existe una relación relativamente alta entre éstos $\left(\mathrm{R}^{2}=0.951\right)$. Tal afirmación está relacionada con el comportamiento gráfico en la Figura 3i, que relaciona magnesio en función de sulfatos. En ella un $66 \%$ de las muestras se distribuye alrededor de la equilínea mostrada, señalando un aporte sustancial del proceso antes indicado.
De manera análoga a los resultados obtenidos por Garfias et al. (2010), puede inferirse que para los sulfatos con respecto a calcio, magnesio y bicarbonatos existe, ya sea una fuente común de origen o similares procesos responsables de sus concentraciones en las muestras analizadas, esto a partir de la alta correlación de los sulfatos con ellos $\left(\mathrm{R}^{2}=0.9225,0.951\right.$ y 0.9823 , respectivamente). En definitiva, puede concluirse que los procesos de disolución de minerales de silicatos, halita, sulfato de magnesio, calcita y dolomita, así como los procesos de intercambio iónico, son los principales involucrados en la composición química del agua en la zona de estudio.

Especial mención de análisis tiene la importancia de los procesos de dedolomitización en la composición química del agua, los cuales se evidencian temporalmente en la misma. En la dedolomitización, ante un incremento de sulfatos, incrementos de calcio, magnesio y cloruros (Figuras $3 g, 3 i$ y $3 j$ ), van asociados a reducciones en el $\mathrm{pH}$. Este proceso es corroborado por la relación inversa existente entre los bicarbonatos y el pH (Figura 3k), generando una subsaturación respecto a dolomita, y provocando su disolución con un consecuente incremento en las concentraciones de magnesio en el agua (López-Chicano et al., 2001). De manera análoga a los resultados obtenidos por Garfias et al. (2010), los procesos de dedolomitización incrementan los contenidos de calcio y magnesio, mientras que hacen decrecer los de alcalinidad y $\mathrm{pH}$, por lo que se considera un proceso fundamental en la zona.

Además de la disolución de minerales carbonatados, el enriquecimiento con $\mathrm{HCO}_{3}^{-}$puede originarse de la disolución de $\mathrm{CO}_{2}$ atmosférico y del suelo (Jeong, 2001), derivado de la descomposición de la materia orgánica, la cual podría ser una fuente adicional de bicarbonatos en la zona de estudio.

En ese sentido, y como puede intuirse a partir de los resultados antes mostrados, el grado de mineralización de las aguas en un acuífero kárstico depende de la conjunción de los factores volumen de recarga, tiempo de residencia, las interacciones 

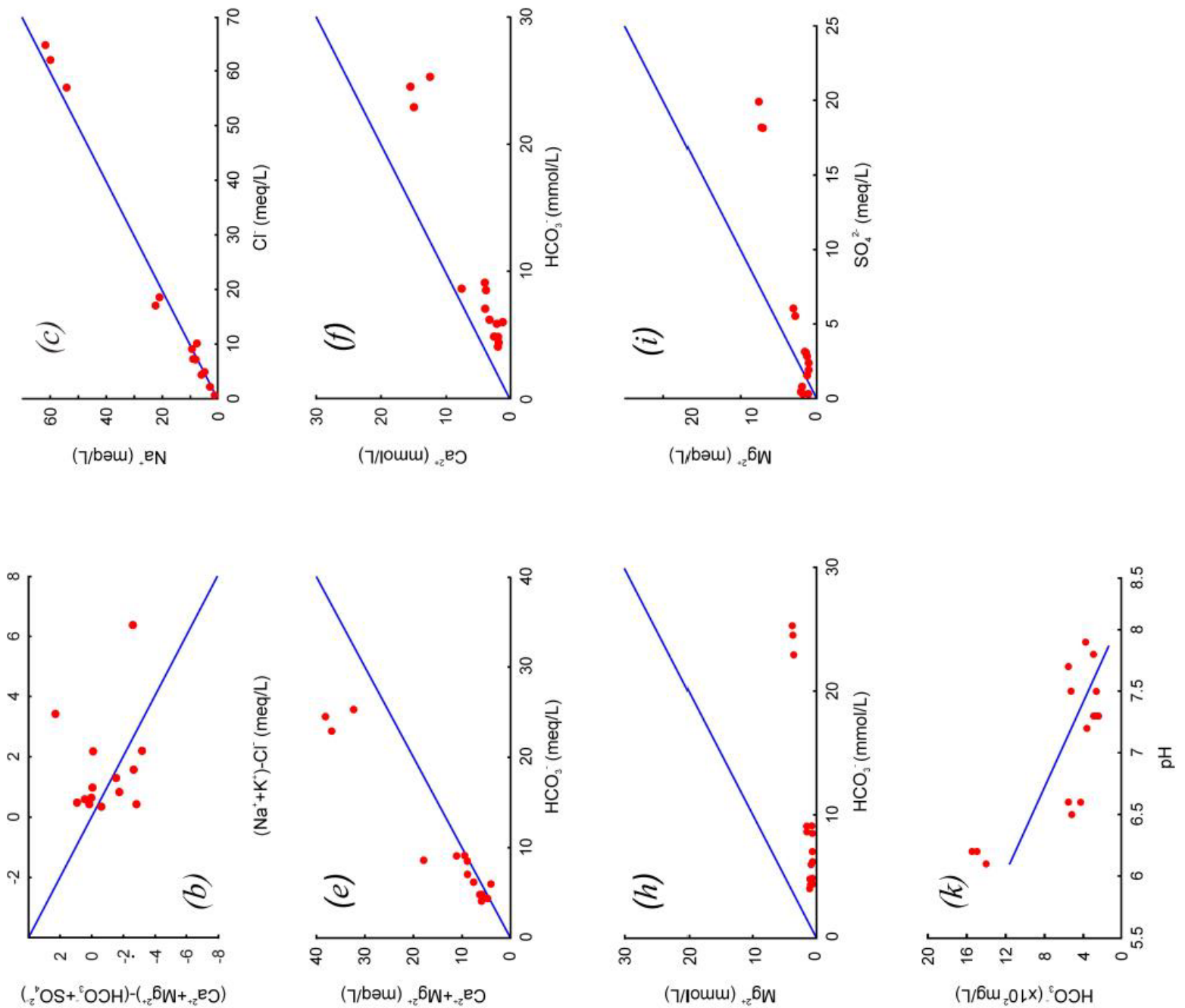

$\left(\right.$. $\left.\mathrm{OS}+{ }^{\mathrm{C}} \mathrm{OOOH}\right)-\left({ }_{+2} \mathrm{C} \mathrm{W}+{ }_{+2} \mathrm{eJ}\right)$

$$
(7 / \text { bəu) })_{+z} 6 W+{ }_{+z} e J
$$

$\left(7 / 6 m_{z} \mathrm{Olx}\right)^{\mathrm{f}} \mathrm{O} \mathrm{OH}$

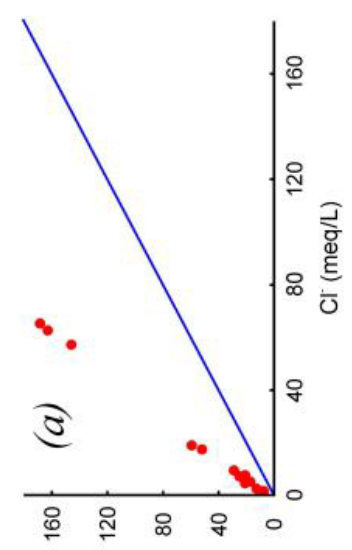

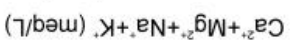
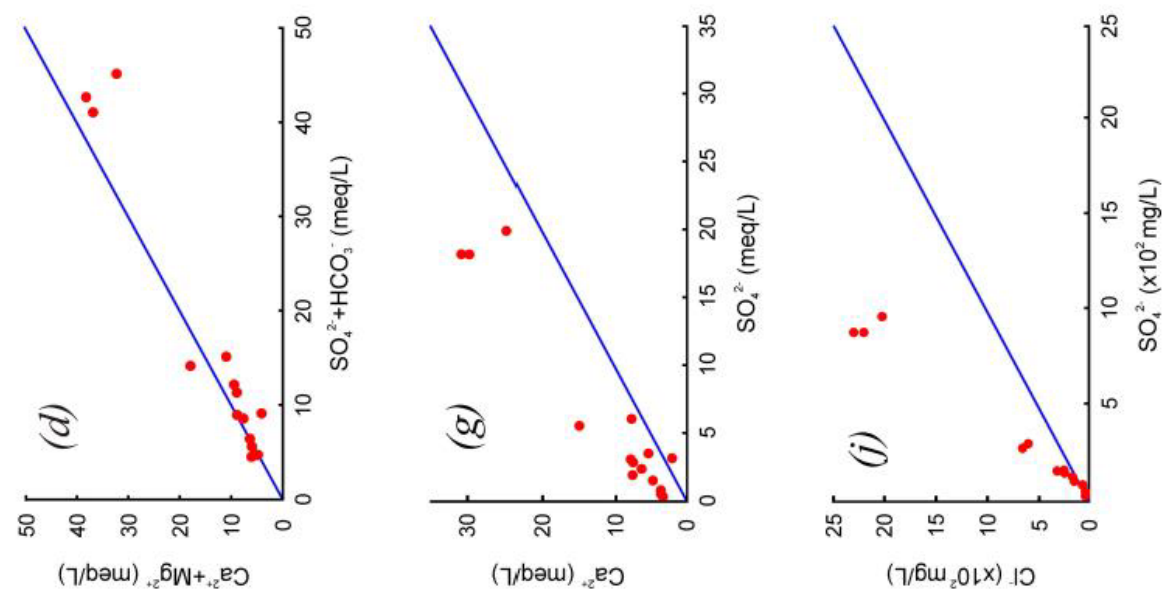

Figura 3 Relaciones químicas entre aniones y cationes mayores para el período de muestreo del año 2019: (a) Cationes mayoritarios y cloruros, (b) $\left(\mathrm{Ca}^{2+}+\mathrm{Mg}^{2+}\right)-\left(\mathrm{HCO}_{3}+\mathrm{SO}_{4}{ }^{2}\right)$ y $\left(\mathrm{Na}^{+}+\mathrm{K}^{+}\right)-\mathrm{Cl}$, (c) $\mathrm{Na}^{+}$y Cl$;($d $)\left(\mathrm{Ca}^{2+}+\mathrm{Mg}^{2+}\right)$ y $\left(\mathrm{SO}_{4}{ }^{2}+\mathrm{HCO}_{3}{ }^{-}\right),(e)\left(\mathrm{Ca}^{2+}+\mathrm{Mg}^{2+}\right)$ y $\mathrm{HCO}_{3}$; $(f) \mathrm{Ca}^{2+}$ y $\mathrm{HCO}_{3}$; (g) $\mathrm{Ca}^{2+} \mathrm{y} \mathrm{SO}_{4}{ }^{2-}$, (h) $\mathrm{Mg}^{2+}$ y $\mathrm{HCO}_{3}$, (l) $\mathrm{Mg}^{2+} \mathrm{y} \mathrm{SO}_{4}{ }^{2-}$, (j) $\mathrm{Cl}^{-}$y $\mathrm{SO}_{4}{ }^{2-}$ y (k) $\mathrm{HCO}_{3}^{-}$y pH. 
generadas en el binomio agua-roca en el acuífero y el componente gaseoso del subsuelo $\left(\mathrm{CO}_{2}\right)$. El dióxido de carbono es generado en los suelos por la degradación de la materia orgánica y la respiración radicular, por ello el uso de suelo y la actividad biológica están directamente relacionadas con él.

De esta forma, con el objetivo de profundizar la relación existente entre el contenido de $\mathrm{EpCO}_{2}$ de las muestras y las concentraciones de elementos de interés, la Figura 4 muestra las relaciones de las variables $\mathrm{pH}$, aniones, dureza y cationes en función del $\mathrm{EpCO}_{2}$. La relación existente entre el $\mathrm{pH}$ y $\mathrm{EpCO}_{2}$ es negativa para los datos analizados (Figura 4a), situación que concuerda con los resultados obtenidos por Jeong (2001), lo que estaría relacionado con la provisión y consumo de dióxido de carbono en el proceso de evolución del agua. En este aspecto, los valores de $\mathrm{pH}$ varían en el rango de 6.1 a 7.9, lo que estaría generando la presencia de, aproximadamente, $30 \%$ de $\mathrm{HCO}_{3}$ junto a un $70 \%$ de ácido carbónico $\left(\mathrm{H}_{2} \mathrm{CO}_{3}\right)$, para el límite inferior $(\mathrm{pH}=6.1)$, contra un 95\% de $\mathrm{HCO}_{3}^{-}$y $5 \%$ de $\mathrm{H}_{2} \mathrm{CO}_{3}$, para el límite superior ( $\mathrm{pH}=7.9$ ), medido en las muestras analizadas para 2019. Esto estaría indicando que, ante un pH más básico, podrían esperarse concentraciones menores de $\mathrm{EpCO}_{2}$, situación que puede ser corroborada en la relación establecida en la Figura $4 a$.

En la Figura 4 puede verse que altos niveles de $\mathrm{EpCO}_{2}$ se corresponden con altos niveles de sulfatos, cloruros, dureza total, y sodio+ potasio para las fuentes termales y, en mucha menor proporción, para los otros tipos de fuentes (manantiales no termales, pozos y fuentes superficiales). Los resultados difieren de los obtenidos por Jeong (2001), quien no asigna el alto contenido de $\mathrm{CO}_{2}$ a actividad magmática en su zona de estudio; más bien, encausa su origen a la infiltración de aguas ricas en contaminantes orgánicos. En contraposición a este autor, los resultados registrados en la presente investigación coindicen con los obtenidos por Cerón et al. (1998), quienes determinaron un enriquecimiento en bicarbonatos junto a concentraciones altas de $\mathrm{CO}_{2}$ en aguas termales del sureste de las Cordilleras Béticas. Adicionalmente, este factor determinaba en dicha zona, junto a procesos de dedolomitización, la formación de travertinos que pueden hallarse en ella, algo que se evidencia en algunas áreas de la presente investigación.

La investigación retomó un enfoque adicional para evaluar el efecto que tiene el $\mathrm{EpCO}_{2}$ en la conformación de las características fisicoquímicas del agua. Para ello la Figura $2 c$ muestra la relación entre la concentración determinada de éste en el agua y su clasificación respecto del diagrama de Piper para 2019 (Figura 2b). En este sentido, y retomando la metodología desarrollada por Jeong (2001), pueden establecerse dos rangos principales: (1) muestras cuyo contenido de $\mathrm{EpCO}_{2}$ oscila entre 8 y 84, que contemplan la totalidad de pozos, tres muestras superficiales y dos manantiales no termales (puntos 3-6, 8-10 y 13-14, Tabla 1) y (2) aquellas muestras con un $\mathrm{EpCO}_{2}$ arriba de los 270 , en las que se incluyen tres manantiales considerados no termales y tres procedentes de fuentes termales, que pueden considerarse contaminadas por fuentes geogénicas de la zona y que sustentarían los procesos de mezcla entre dichas fuentes al compartir esta característica común de la alta concentración de $\mathrm{EpCO}_{2}$.

La afirmación anterior se sustenta en el hecho de lo expresado por Jeong (2001) respecto de la implementación de esta metodología, pues afirma que el vínculo establecido entre el contenido de $\mathrm{CO}_{2}$ de las muestras analizadas y su clasificación química en el diagrama de Piper (Figura 2b), puede ser utilizado como "una herramienta analítica para identificar la contaminación orgánica e inorgánica del agua subterránea". Por ello, las altas concentraciones de $\mathrm{EpCO}_{2}$ determinadas en las "fuentes no termales" (puntos 1, 2 y 12, Tabla 1), y que son compartidas con las fuentes termales (puntos 7, 11 y 15, Tabla 1), pueden ser adjudicadas a procesos endógenos del sistema acuífero relacionados a la mezcla de dichas fuentes.

\subsection{ANÁLISIS DE GOMPONENTES PRINGIPALES (AGP)}

\subsubsection{PROCESOS HIDROGEOQUÍMICOS}

Numerosos factores geológicos están involucrados en la composición química del agua en la zona de estudio, en la que la disolución de minerales 
carbonatados, como la calcita y dolomita, es predominante. Adicionalmente, factores antropogénicos derivados del uso del suelo también ejercen influencia, en grados diversos, en la contaminación del agua en la zona con elementos que representan un riesgo potencial a la salud de la población. Los principales procesos involucrados en la conformación de las características químicas del agua han sido destacados previamente a través del diagrama de Piper (Figura 2) y del análisis de relaciones iónicas de importancia en la zona (Figura 3 y 4 ).
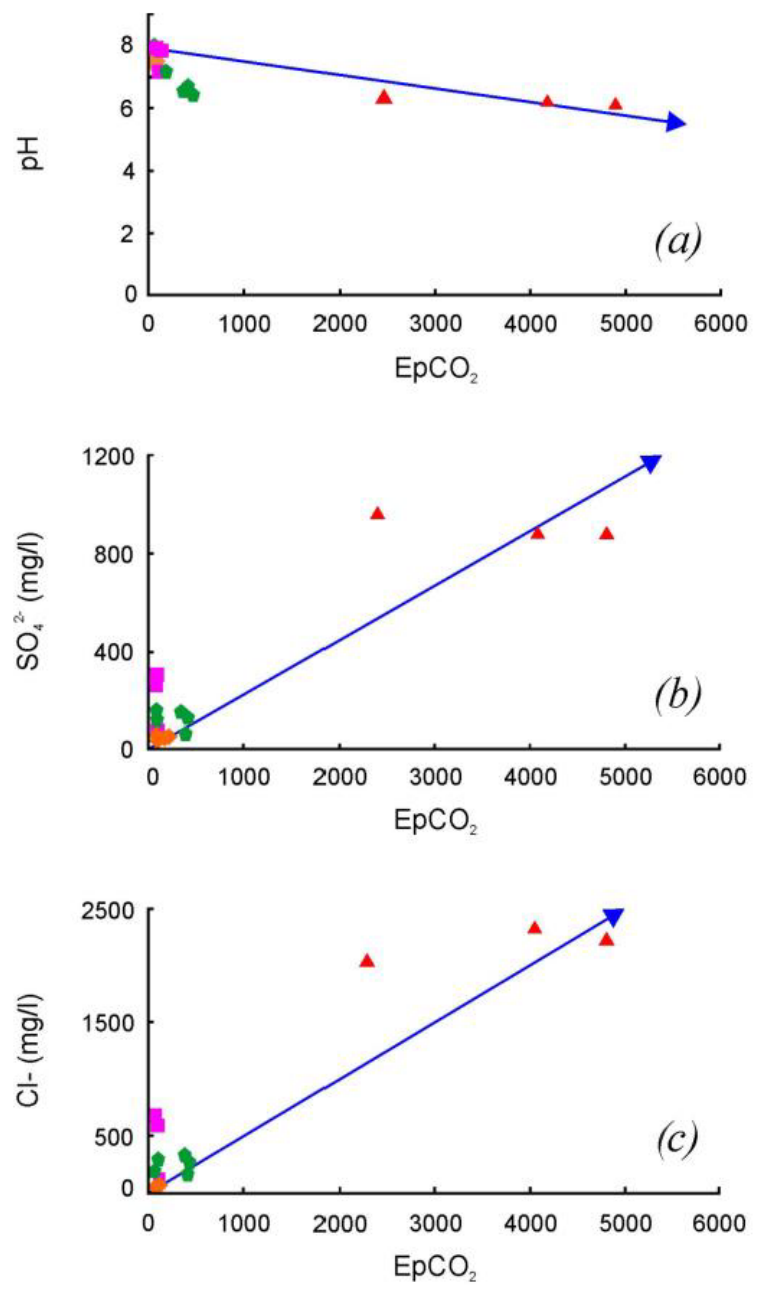

Las técnicas de análisis multivariado, entre las que destaca el Análisis de Componentes Principales (ACP), se formulan como una alternativa adicional a las técnicas convencionales de análisis hidroquímico (diagramas de Piper, Schöeller-Berkalof y Stiif, entre otros) que ya han sido implementadas en la zona de estudio. De igual forma, se consolidan en una elección, como lo postula Hair et al. (2014), para la reducción de un número grande original de variables fisicoquímicas $\left(\mathrm{pH}, \mathrm{SDT}, \mathrm{Ca}^{2+}, \mathrm{Mg}^{2+}\right.$, entre otros), hacia un número nuevo, menor de ellas, denominadas componentes o factores (Tabla
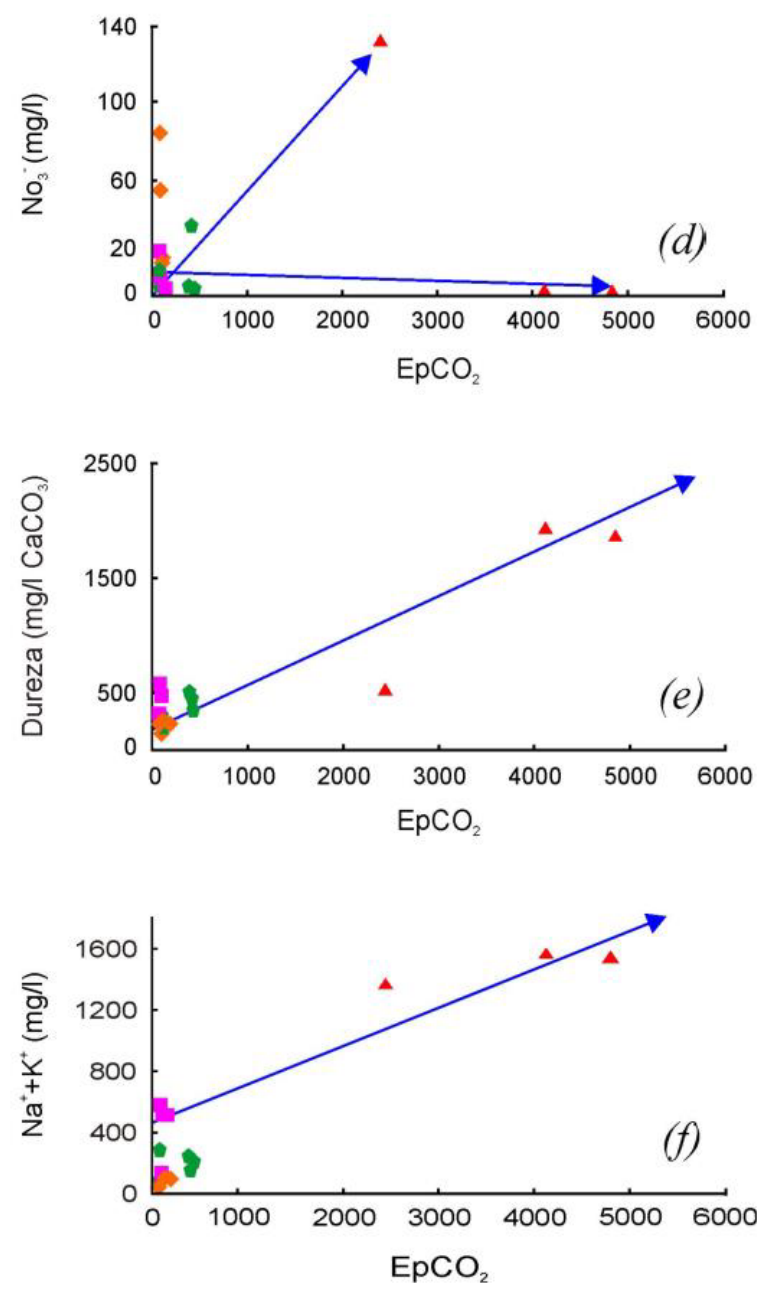

Leyenda

$\Delta$ Termales $\bullet$ No termales $\|$ Superficiales $\$$ Pozo

Figura 4 Gráfica de los niveles de: $(a)$ pH, $(b)$ Sulfatos, $(c)$ Cloruros, $(d)$ Nitratos, $(e)$ dureza total y $(f)$ sodio+potasio en función del EpCO para las muestras de agua para el período de muestro del año 2019. 
Tabla 2. Análisis de Componentes Principales con rotación Varimax. Los valores en negritas representan las variables identificadas como representativas en cada factor.

\begin{tabular}{|c|c|c|c|c|}
\hline \multirow[t]{2}{*}{ Parámetro } & \multicolumn{2}{|c|}{$\begin{array}{c}\text { Componente } \\
\text { principal } \\
2015\end{array}$} & \multicolumn{2}{|c|}{$\begin{array}{c}\text { Componente } \\
\text { principal } \\
2019\end{array}$} \\
\hline & 1 & 2 & 1 & 2 \\
\hline $\mathbf{T}^{\circ}$ & 0.217 & 0.909 & 0.100 & 0.910 \\
\hline pH & -0.481 & -0.775 & -0.240 & -0.838 \\
\hline $\mathbf{C E}$ & 0.596 & 0.738 & 0.760 & 0.637 \\
\hline SDT & 0.818 & 0.571 & 0.760 & 0.635 \\
\hline $\mathrm{Ca}^{2+}$ & 0.760 & 0.641 & 0.589 & 0.708 \\
\hline $\boldsymbol{K}^{+}$ & 0.937 & 0.337 & 0.870 & 0.460 \\
\hline $\mathrm{Mg}^{2+}$ & 0.466 & 0.788 & 0.322 & 0.808 \\
\hline $\mathrm{Na}^{+}$ & 0.887 & 0.453 & 0.840 & 0.520 \\
\hline $\mathrm{Cl}^{-}$ & 0.909 & 0.409 & 0.866 & 0.484 \\
\hline $\mathrm{NO}_{3}^{-}$ & -0.730 & -0.456 & -0.700 & 0.142 \\
\hline $\mathrm{SO}_{4}{ }^{2-}$ & 0.888 & 0.444 & 0.824 & 0.533 \\
\hline $\mathrm{HCO}_{3}^{-}$ & 0.640 & 0.760 & 0.617 & 0.778 \\
\hline As & 0.882 & 0.353 & 0.877 & 0.373 \\
\hline $\mathrm{EpCO}_{2}$ & 0.433 & 0.814 & 0.308 & 0.869 \\
\hline Eigenvalor & 11.80 & 1.07 & 6.3 & 6.01 \\
\hline $\begin{array}{c}\text { Varianza } \\
\text { explicada } \\
(\%)\end{array}$ & 84.30 & 7.63 & 45.01 & 42.95 \\
\hline $\begin{array}{c}\text { Varianza } \\
\text { acumulada } \\
(\%)\end{array}$ & 84.30 & 91.93 & 45.01 & 87.96 \\
\hline
\end{tabular}

2). Estos factores presentan una mínima pérdida de información y permiten la inferencia de los procesos hidrogeoquímicos que tienen lugar en la zona (Subyani y Al-Ahmadi, 2010; Subba Rao et al., 2007; McLeod et al., 2017).

Como un primer paso para la definición de las nuevas variables, se aplicó el criterio de Kaiser para identificar el número de componentes principales (CP) a mantener para fines de esta investigación. En función del mismo, se conservaron solamente aquellos cuyo eigenvalor fue superior a la unidad, manteniendo así, para ambos períodos de muestreo, dos CP que explicaban el $91.93 \%$ (2015) y $87.96 \%$ (2019) de la varianza en los datos, los cuales se consideran adecuados en términos de representatividad estadística de los procesos hidroquímicos estudiados. La Tabla 2 muestra las cargas de las variables para ambos períodos como resultado de la rotación Varimax con la normalización Kaiser, aplicada para facilitar la interpretación de los factores seleccionados. En función del tamaño de la muestra utilizado para esta investigación, se consideraron como representativas, para motivos de análisis, aquellas variables cuyos cargas fueron mayores o iguales a 0.7 (Hair et al., 2014), las cuales se muestran en negrita para fines de visualización en la tabla antes mencionada. 
Para ambos períodos, el CP-I está relacionado positivamente con aquellos elementos vinculados a los procesos de salinidad, en la que se involucran procesos geogénicos como antropogénicos de composición química del agua: sólidos disueltos totales, potasio, sodio, cloruros, nitratos, sulfatos y arsénico. Este CP explica el $84.30 \%$ y $45.01 \%$ de la varianza de los datos para 2015 y 2019, respectivamente. Es importante mencionar que existe una fuerte correlación entre los SDT con calcio, sodio, magnesio y cloruros $\left(\mathrm{R}^{2}=0.9537\right.$, 0.9953, 0.9385 y 0.9975 , respectivamente), implicando que estas variables químicas seguirán una tendencia similar, por lo que se esperaría que este proceso de salinidad incremente a medida que lo haga la interacción entre el agua subterránea y las formaciones geológicas. Con ello puede deducirse que la alta contribución de la variable SDT a este CP se debe a la disolución iónica en el agua.

Igualmente, la participación de los iones mayoritarios (sodio, cloruros y potasio) está asociada a la disolución mineral y a la interacción agua-roca en el acuífero (Jiang et al, 2015), así como a la influencia geotermal (Halim et al., 2010), aspecto, este último, de importancia en la conformación de las características químicas del agua de la zona de estudio. Este hecho ya ha sido evidenciado en el diagrama de Piper (Figura 2), y se considera de relevancia en las concentraciones de arsénico registradas en el medio acuoso, situación que puede ser corroborada al verificar la fuerte carga que este elemento tiene en el CP-I (0.882).

A partir de ello, puede inferirse que este CP-I está influenciado por factores: (1) climáticos, puesto que en él intervienen parámetros fisicoquímicos relacionados a la disolución mineral (SDT, $\left.\mathrm{K}^{+}, \mathrm{Na}^{+}, \mathrm{Cl}\right)$, (2) geogénicos, relacionados a la presencia de aguas termales en la zona (As presenta una carga superior a 0.8 para ambos períodos de muestreo (Tabla 2)) y (3) antropogénicos, proceso manifestado por la presencia de nitratos en este CP. Factores todos ellos que, en su conjunto, definen las características del agua en la zona de estudio.

Esta individualización se sustenta en el principio inherente a la técnica de análisis multivariado del ACP, el cual permite la inferencia de procesos individuales, independientes los unos de los otros. Esto se confirma por lo expresado por Subba Rao et al. (2007): "Cada componente principal puede ser usado para interpretarse como un proceso hidrogeoquímico específico o como diferentes procesos a través de un examen de las cargas (de las variables fisicoquímicas registradas en los CP)". Este CP, y sus elementos positivamente relacionados (Tabla 2), afectan, sobre todo, los puntos de muestreo 1-6, 11 y 14-15 (Tabla 1, Figura 1), considerando que éstos presentan puntuaciones factoriales mayores a cero (Figuras $5 c$ y $d$ ), por lo que se consideran los puntos con mayor índice de disolución iónica, entre los que cabe destacar la presencia de arsénico a distintas concentraciones.

Adicionalmente, el CP-II está relacionado positivamente con aquellos elementos vinculados con los procesos de alcalinidad que tienen lugar en la zona: pH, magnesio, calcio, bicarbonatos, contenido de dióxido de carbono y temperatura. Debe destacarse de la Tabla 2 que, para ambos períodos, las variables $\mathrm{pH}$ (CP-II) y nitratos (CP-I) presentan una carga negativa, lo que implica que aquellos sitios con puntuaciones factoriales negativas (modo Q del ACP) tendrán tendencia a valores más altos de ellas y, relativamente menores, de las otras variables consideradas, es decir, serán aguas más alcalinas y de mayor contenido de nitratos. Las variables con carga positiva en el CP-II afectan, sobre todo, a los puntos 7, 10-12 y 15 , ya que éstos presentan puntuaciones factoriales positivas en él.

Por otra parte, profundizando en algunas variables de interés en la zona, puede mencionarse que las altas concentraciones de $\mathrm{HCO}_{3}{ }^{-}$en las muestras pueden tener su origen, tanto a partir de la disolución de minerales carbonatados (Figuras 2 y 3 ) como de la degradación de la materia orgánica, por lo que el CP-II podría ser indicativo de procesos naturales donde la materia orgánica juega un papel importante. Halim et al. (2010) sugieren que la degradación de esta materia orgánica podría tener una función en los procesos de óxido reducción, potenciando con ello la movilización de arsénico en el medio acuífero, y considerándose 
así éste un mecanismo posible de enriquecimiento del metaloide en la zona. Tal situación puede sustentarse en la moderada correlación existente entre el arsénico y los bicarbonatos $\left(\mathrm{R}^{2}=0.6887\right)$ y la carga de este último (0.640) en el CP-I, que puede considerarse representativa, desde el punto de vista estadístico, como factor de influencia e interacción con el arsénico, implicando con ello su movilización en un ambiente anóxico en la zona de estudio.

En este sentido, Gupta y Gupta (2013), expresan que el potencial de óxido reducción (ORP), junto al pH, pueden ser considerados los dos factores principales que controlan la especiación de arsénico y determinan su solubilidad en el agua. De esta forma, para establecer la influencia de este factor (ORP) en la zona de estudio, fue aplicada la especiación de arsénico presente utilizando el programa PHREEQC (Avilés et al., 2013) para los puntos 1 y 2, cuyo valor promedio de Eh es de $82.95 \mathrm{mV}$, pudiendo así determinarse un $97.2 \%$ de especies de $A s(V$ ). Estos resultados de influencia coinciden con los obtenidos por Rasool et al. (2016), quienes determinaron una predominancia de la misma especie química de arsénico en aguas bajo condiciones oxidantes en estudios de hidrogeoquímica en Tehsil Mailsi, Punjab, Pakistan.

De igual forma, Zheng et al. (2004), citado por Halim et al. (2010), especifican que la mayoría de los cationes mayores liberados son incrementados a partir del $\mathrm{CO}_{2}$ derivado de la degradación, tanto óxica como anóxica de la materia orgánica. Por esta razón, explican que el proceso general para la liberación de las altas concentraciones de $\mathrm{HCO}_{3}^{-}$ en la zona puede derivarse de las siguientes reacciones químicas:

$$
\mathrm{CH}_{2} \mathrm{O}(\text { materia organica })+\mathrm{O}_{2} \rightarrow \mathrm{H}_{2} \mathrm{O}+\mathrm{CO}_{2}
$$

$$
\mathrm{CaMg}\left(\mathrm{CO}_{3}\right)_{2}+\mathrm{CO}_{2}+\mathrm{H}_{2} \mathrm{O} \rightarrow \mathrm{Mg}^{2^{+}}+2 \mathrm{HCO}_{3}^{-}+\mathrm{CaCO}_{3}
$$

$$
\mathrm{CaCO}_{3}+\mathrm{CO}_{2}+\mathrm{H}_{2} \mathrm{O} \rightarrow \mathrm{Ca}^{2^{+}}+2 \mathrm{HCO}_{3}^{-}
$$

En ese sentido, esta posible generación de $\mathrm{HCO}_{3}$, a partir de la materia orgánica, podría estar relacionada con la liberación de arsénico, pues, como lo demuestran DeVore et al. (2019), este compuesto podría tener relación directa con el mecanismo de liberación, vía desplazamiento competitivo de iones de $A s(V)$ que pudieran estar débilmente unidos a la superficie de los sólidos del subsuelo.

De manera complementaria, a partir de las relaciones establecidas entre los elementos en el plano bidimensional dictado por los componentes principales extraídos (Figuras $5 a$ y $5 b$ ), pueden definirse tres grupos de variables, el primero está definido por $\mathrm{EpCO}_{2}$ y magnesio, mientras que el segundo, por bicarbonatos y calcio y el tercero está conformado por otros elementos involucrados en la composición química del agua, que incluye a los sulfatos, arsénico, sodio, potasio, cloruros, sólidos disueltos totales y conductividad eléctrica. Estas agrupaciones pueden atribuirse a la disolución de los estratos minerales existentes en el acuífero estudiado, que han sido descritas en el apartado 5.2. Análisis hidroquímico: minerales evaporíticos (anhidrita y halita), así como de calcita, dolomita y aquellos de sulfato de magnesio. La relación cercana, determinada por el ACP entre el sodio y los cloruros, confirmaría su origen común en el medio acuífero (Figura 3c).

Un hecho importante que debe de resaltarse en este punto es que, para ambos períodos de muestreo, todos los elementos relacionados al enriquecimiento iónico del agua tienen una relación inversa con el $\mathrm{pH}$ (ubicado en una posición opuesta en el diagrama de ACP, Figuras $5 a$ y $5 b$ ), implicando con ello que las aguas más mineralizadas, o al menos las más enriquecidas en elementos sensibles al potencial de óxido reducción, sulfatos y arsénico, tenderán a ser menos alcalinas (Garfias et al., 2010). Así pues, puede considerarse éste (pH) como uno de los principales parámetros involucrados en la conformación química del agua, lo que es particularmente importante en términos de las concentraciones de arsénico en ella, considerando que es uno de los parámetros fisicoquímicos que participan tanto en su especiación como en su solubilidad en el medio acuífero (Ali et al., 2019). 
Similar consideración puede establecerse respecto a los nitratos, parámetro que ocupa una posición lejana y opuesta respecto de los otros elementos analizados, infiriéndose, de esta manera, un proceso distinto de origen, específicamente antropogénico, responsable de su ingreso al medio acuoso. Por otro lado, todos los elementos relacionados a la mineralización del agua se hallan en una posición cercana al $\mathrm{EpCO}_{2}$, con lo que puede concluirse el involucramiento de este parámetro en los procesos naturales de disolución, aspecto que confirmaría las relaciones químicas visualizadas en la Figura 4.

$\mathrm{Al}$ comparar las gráficas de las cargas en el plano bidimensional establecido por los dos CP extraídos para los parámetros analizados en los años 2015 y 2019 (Figuras $5 a$ y $5 b$ ), puede determinarse que las mayores variaciones se presentan para el calcio, la conductividad eléctrica, los nitratos y el $\mathrm{pH}$. Esto pondría en evidencia los procesos de disolución/concentración de elementos en función de las condiciones de flujo, la precipitación y la influencia de las actividades antropogénicas/ agrícolas desarrolladas.

Estos resultados de tendencia estacional son reforzados con los obtenidos por Satyaji-Rao et al. (2010), quienes determinaron una variación significativa de influencia, principalmente para el calcio, en función de los cambios de las condiciones climáticas derivadas de las épocas de muestreo de su investigación. Ellos establecieron, sin lugar a dudas, una relación inherente entre dichas condiciones, expresadas en términos de la precipitación, y las condiciones hidrogeológicas, las cuales, en conjunto, determinan la mayor o menor concentración de los elementos constitutivos del agua en las zonas de estudio y, señalan, las variaciones que tienen lugar en los períodos analizados en la presente investigación (Figura $5 a$ y $5 b$ ). De este análisis se desprende que el modo $\mathrm{R}$ del Análisis de componentes principales corrobora los procesos ya definidos en la etapa previa de relaciones químicas mostradas. Su aporte radica en destacar, separar e individualizar entre los procesos antropogénicos y geogénicos que determinan la composición química del agua en la zona de estudio e identifican los elementos que en ellos intervienen.

\subsubsection{PUNTUACIONES FACTORIALES DE LOS COMPONENTES PRINGIPALES}

Las Figuras $5 c$ y $5 d$ presentan la distribución de los sitios de muestreo respecto de las puntuaciones factoriales extraídas para ambos períodos que están siendo considerados (modo Q del ACP). Cuatro grupos de sitios con características similares pueden ser inferidos:

El grupo "A" reúne sitios con características termales, con altas tasas de mineralización, elevado contenido de sulfatos, CE, SDT, bicarbonatos y arsénico, manteniéndose, en el tiempo, dentro del polo correspondiente a los elementos de salinidad. Este grupo se corresponde con aguas del tipo $\mathrm{Na}^{+}$-Clt y presentan, predominantemente, puntuaciones positivas en el CP-I.

El grupo "B", para ambos períodos, coincide con los pozos, todos ubicados en el municipio de Tonatico, con aguas relativamente de baja mineralización, bajas concentraciones promedio de $\mathrm{CE}$ (538 $\mu \mathrm{S} / \mathrm{cm})$ y SDT (272 mg/l) y, en general, las menores concentraciones de cationes y aniones mayoritarios, lo cual se suma a las más bajas concentraciones de arsénico.

Este análisis confirma los resultados obtenidos en el diagrama de Piper (Figura 2), en el que se ubican dentro del grupo $\mathrm{Ca}^{2+}-\mathrm{HCO}_{3}^{-}$, de aguas frescas, que han pasado por procesos de disolución de minerales carbonatados. El único parámetro químico que limitaría la aptitud de uso para consumo humano de estas fuentes estaría determinado por la concentración promedio de nitratos, que asciende a $57.44 \mathrm{mg} / \mathrm{l}$, lo que supera el límite máximo permisible de $50 \mathrm{mg} / 1$ establecido desde WHO (2011). En general, este grupo se caracteriza por tener puntuaciones negativas para ambos componentes principales.

El grupo "C", aunque presenta pequeñas variaciones, en general tiende a mantener su posición dentro del plano bidimensional establecido por las puntuaciones factoriales (Figuras $5 c$ y $5 d$ ). Este grupo es prioritario, pues incluye las fuentes MNT1 y MNT2 (Tabla 1), que son utilizadas para la provisión de aguas para consumo humano en el muncipio de Ixtapan de la Sal. En ellas, el arsénico se consolida como el principal elemento limitante 

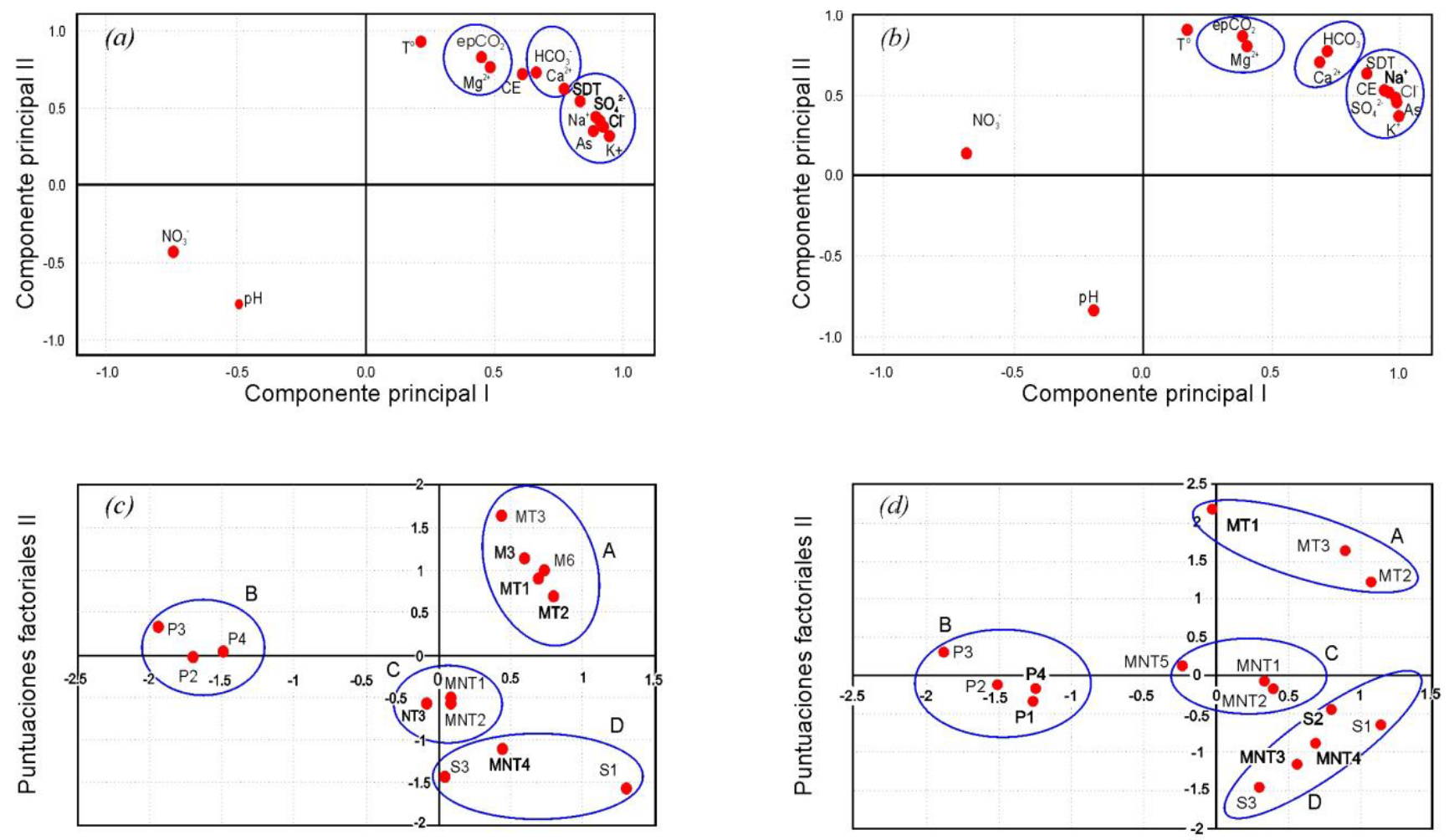

Puntuaciones factoriales I

Puntuaciones factoriales |

Figura 5 Distribución bidimensional de las variables en las componentes principales (a) 2015 y (b) 2019 y de los sitios de muestreo en las puntuaciones factoriales en: (c) 2015 y (d) 2019.

de calidad, con una concentración promedio de $0.33 \mathrm{mg} / 1$ (Límite máximo permisible de 0.01 mg/l (WHO, 2011)). Para 2019 (Figura 5d), estas fuentes tienden a acercarse un poco más a las puntuaciones del grupo "A", infiriéndose, con ello, un incremento en los procesos de mezcla evidenciados con el diagrama de Piper (Figura 2c).

Muy posiblemente, pueden ser aguas que evolucionaron, por el proceso antes mencionado, desde el tipo $\mathrm{Na}^{+}$- $\mathrm{Cl}$ hacia $\mathrm{Ca}^{2+}-\mathrm{Mg}^{2+}-\mathrm{Cl}$, por su paso por minerales carbonatados, así como por los procesos de intercambio iónico que tienen lugar en el acuífero. Su movimiento vertical en el eje del CP-II, relacionado a $\mathrm{pH}$ y $E p C O_{2}$, puede ser indicativo de la participación de estos parámetros fisicoquímicos en los procesos de gasificación-desgasificación y en el enriquecimiento con bicarbonatos y arsénico, principalmente. En general se caracterizan por ser aguas cuyas puntuaciones en ambos componentes principales no son mayores a 0.5 .

El grupo denominado " $\mathrm{D}$ ", que se corresponde con aguas de características $\mathrm{Ca}^{2+} \mathrm{HCO}_{3}^{-}, \mathrm{Ca}^{2+}$ $\mathrm{Mg}^{2+}-\mathrm{Cl}$ y $\mathrm{Na}^{+}-\mathrm{Cl}$, presenta puntuaciones altas en el CP-I, relacionado a la salinidad, lo que determina que presenten concentraciones de sulfatos, arsénico, CE y SDT incluso mayores a los sitios ubicados en el grupo "C". Por el lado contrario, presentan puntuaciones negativas en el CP-II, determinando valores de $\mathrm{pH}$ más alcalinos.

Una conclusión adicional que puede desprenderse de las Figuras $5 c$ y $d$, y que deriva de la capacidad del sistema de mantener las fuentes reunidas en grupos más o menos constantes en el tiempo con la realización del ACP, es el hecho de que éste puede considerarse un sistema capaz de homo- 
Tabla 3. Valores promedio de los parámetros fisicoquímicos en los grupos identificados a partir del modo Q del Análisis de Componentes Principales para el año 2019.

\begin{tabular}{|c|c|c|c|c|}
\hline \multirow{2}{*}{ Variable } & \multicolumn{4}{|c|}{ Grupo identificado } \\
\hline & $\mathbf{A}$ & B & C & D \\
\hline $\mathbf{C E}$ & 10265.1 & 538 & 1721.7 & 2178.1 \\
\hline SDT & 4996.9 & 272 & 845 & 1076.8 \\
\hline $\boldsymbol{K}^{+}$ & 131.3 & 1.6 & 20.6 & 25.72 \\
\hline $\mathrm{Na}^{+}$ & 1347.3 & 21.6 & 179.7 & 276.3 \\
\hline $\mathrm{Cl}-$ & 2172.4 & 15.6 & 244.8 & 354.9 \\
\hline $\mathrm{SO}_{4}{ }^{2-}$ & 900.8 & 22.8 & 125.5 & 179.3 \\
\hline As & 1013 & 10 & 293.3 & 284 \\
\hline $\mathrm{NO}_{3}^{-}$ & 44.7 & 44.2 & 13.9 & 8.8 \\
\hline $\mathbf{T}^{\circ}$ & 31.7 & 23.78 & 24.1 & 21.9 \\
\hline $\mathrm{pH}$ & 6.17 & 7.4 & 6.6 & 7.6 \\
\hline $\mathrm{Ca}^{2+}$ & 569.6 & 74.3 & 155.5 & 147.5 \\
\hline $\mathrm{Mg}^{2+}$ & 89.2 & 21.7 & 15.5 & 24.1 \\
\hline $\mathrm{HCO}_{3}^{-}$ & 1479.1 & 268.9 & 501.8 & 423.8 \\
\hline $\mathrm{EpCO}_{2}$ & 3786.3 & 50.4 & 405.1 & 34.6 \\
\hline
\end{tabular}

Unidades: $\mathrm{K}^{+}, \mathrm{Na}^{+}, \mathrm{Cl}^{-}, \mathrm{SO}_{4}^{2-}, \mathrm{NO}_{3}^{-}, \mathrm{Ca}^{2+}, \mathrm{Mg}^{2+}, \mathrm{HCO}_{3}^{-}$y SDT en $\mathrm{mg} / \mathrm{l}, \mathrm{As}$ en $\mu \mathrm{g} / \mathrm{l}, \mathrm{CE}$ en $\mu \mathrm{S} / \mathrm{cm}, \mathrm{T}^{\circ}$ en ${ }^{\circ} \mathrm{C}, \mathrm{pH}$ : unidades de $\mathrm{pH}$.

genizar las aguas, lo que hidrogeológicamente implicaría una baja susceptibilidad de las fuentes muestreadas a la contaminación. Este aspecto hidrodinámico deberá ser evaluado a profundidad en el área de estudio en investigaciones posteriores para lograr una mejor comprensión del sistema acuífero.

La Tabla 3 muestra las concentraciones promedio de las variables involucradas en los grupos identificados en el modo Q del ACP. Con ella pueden visualizarse los cambios que las variables de composición físico-química del agua van teniendo en función de la posición del grupo respecto de los ejes de puntuaciones factoriales. Puede notarse que para 2019, conforme disminuyen las puntuaciones en el eje de "Puntuaciones factoriales I" (Figura $5 d$ ), las variables $\mathrm{CE}, \mathrm{SDT}, \mathrm{K}^{+}, \mathrm{Na}^{+}$, $\mathrm{Cl}, \mathrm{Mg}^{2+}$ y $\mathrm{SO}_{4}^{2}$ - siguen una concentración en el sentido de los grupos $\mathrm{A}>\mathrm{D}>\mathrm{C}>\mathrm{B}$. De este modo, puede concluirse, en términos de la aplicación del modo Q del ACP, que esta etapa permitió el agrupamiento de los sitios con base en características comunes, ya que estas concentraciones revelan algunas tendencias entre los grupos identificados.

\subsection{ANÁLISIS GEOESTADÍSTICO}

\subsubsection{DEFINICIÓN DE MODELOS DE VARIOGRAMAS}

El uso de herramientas de geoestadística ha cobrado importancia en el estudio de la calidad del agua en diversas partes del mundo (SánchezMartos et al., 2001; Satyaji-Rao et al., 2010; McLeod et al., 2017). Por tal motivo, estas técnicas fueron utilizadas para estudiar la continuidad espacial de las variables seleccionadas: las puntuaciones factoriales de CP-I y CP-II (modo Q del ACP) y las concentraciones de arsénico. La Tabla 4 resume algunos parámetros de importancia 
Tabla 4. Parámetros de ajuste del análisis variográfico para las variables en estudio determinados para el período de muestreo del año 2019.

\begin{tabular}{|c|c|c|c|c|c|c|c|c|c|}
\hline & & \multicolumn{3}{|c|}{ Parámetro variográfico } & \multicolumn{4}{|c|}{ Validación cruzada } \\
\hline Variable & Modelo & $\begin{array}{c}\text { Efecto } \\
\text { Nugget }\end{array}$ & Meseta & $\begin{array}{c}\text { Rango } \\
(\mathbf{m})\end{array}$ & ME & RMSE & CD & EF & CRM \\
\hline CP-I & Gaussiano & 0.19 & 0.77 & 4079.4 & 2.11 & 0.78 & 1.29 & 0.69 & -0.29 \\
\hline CP-II & Gaussiano & 0 & 1.31 & 6324.8 & 0.96 & 0.65 & 0.39 & -1.36 & 0.23 \\
\hline As & Esférico & 0.09 & 4.24 & 5099.6 & 3.47 & 1.34 & 1.60 & 0.41 & 0.90 \\
\hline Referencia & - & - & - & - & 0 & 0 & 1 & 1 & 0 \\
\hline
\end{tabular}

El valor de referencia es el valor esperable bajo un proceso de interpolación "ideal"; unidades de ME y RMSE para las variables CP-I y CP-II son adimensionales, mientras que para $A s$ corresponden a mg/l. CD, EF y CRM son adimensionales.

utilizados en el análisis estructural, así como los resultados de la validación cruzada, desarrollada para la selección del modelo de variograma que brindó el mejor ajuste. El modelo Gaussiano proveyó el mejor ajuste para las variables CP-I y CP-II, mientras que el modelo esférico es el que lo hace para la concentración de $A s$.

Como una forma de establecer una comparación temporal, se aplicó el análisis variográfico a los resultados de la campaña de muestreo de enero de 2015 (Tabla no mostrada), encontrándose resultados distintos en los modelos más representativos para las variables utilizadas. Así pues, el modelo exponencial se ajustó mejor a las variables CP-I y CP-II, mientras que el Gaussiano lo hace para las concentraciones de As. Considerando que el variograma representa la variación espacial de una variable, es probable que este cambio de tendencia pueda explicarse, principalmente, por dos factores: (1) Fechas diferentes de muestreo (enero de 2015 y abril de 2019), que determinan condiciones de flujo distintas, sobre todo, en lo relacionado a las condiciones de precipitación en la zona y (2) diferencias en los puntos de muestreo establecidos para ambas investigaciones.

Esta característica de cambio del análisis variográfico es consistente con las investigaciones realizadas por otros autores, quienes reportan, de manera similar, diferencias significativas de los parámetros meseta, rango y efecto nugget, para distintas épocas de muestreo e interpolación, utilizando el variograma esférico para el mapeo de sus variables de interés (Sánchez-Martos et al., 2001; Satyaji-Rao et al., 2010). Situación que lleva a concluir que existe un control regional del variograma representativo con base en factores climáticos, indiscutiblemente, así como geológicos e hidrogeológicos, determinados por el flujo subterráneo en las zonas de estudio.

Retomando la información brindada en la Tabla 4 , puede verse que algunos de los índices utilizados para la validación cruzada se alejan de su valor "ideal" esperado. Esta variación entre los valores obtenidos experimentalmente y su valor ideal podrían ser ocasionados por el tamaño de muestra utilizado. Webster y Oliver (2014), explican que, ante un aumento del tamaño de muestra, desde 87 a 434 sitios seleccionados para la medición de la variable $\log _{10} K^{+}$en una región agrícola, la suma de los cuadrados de los residuos osciló de 0.01127 a 0.00368 y, la varianza explicada, lo hizo de $43.8 \%$ a $99.4 \%$. Con ello puede concluirse que el tamaño de la muestra se consolida como un factor determinante en los resultados de la predicción lograda con el kriging ordinario para esta investigación. De este modo, ellos identifican el hecho de que, mientras mayor sea el número de datos que se tenga mayor será la exactitud lograda en los índices seleccionados para la determinación del mejor modelo de ajuste para las variables de interés. 
Especial mención debe hacerse respecto a la información relacionada a la validación cruzada, específicamente con los resultados relativos al índice EF (eficiencia del modelo), cuyo valor, para el CP-II, es negativo, indicando que existe una tendencia a que los valores promedio medidos brinden una mejor estimación que los valores simulados por el modelo. Adicionalmente, el coeficiente de masa residual (CRM), negativo para el CP-I, mostraría que la tendencia de los valores simulados es a la sobreestimación, generando, posiblemente, valores en la superficie de predicción que podrían ser mayores de lo que, en campo, serían medidos en una situación real (Homaee et al., 2002). Como consecuencia de las anteriores aseveraciones, puede establecerse que el aumento de los sitios de muestreo para la zona de estudio podría mejorar los resultados de la validación cruzada, así como las superficies de predicción logradas por la metodología de kriging ordinario para las variables en estudio.

\subsubsection{MAPEO BIDIMENSIONAL DE LA DISTRIBUCIÓN DE LAS NUEVAS VARIABLES EN LA ZONA DE ESTUDIO}

Las superficies de predicción e influencia para cada una de las variables de interés se muestran en las Figuras 6 y 7. Puede verse que la tendencia de la predicción para el CP-I, para ambos períodos, es a situar las puntuaciones más altas en el área norte de la zona de estudio, en el municipio de Ixtapan de la Sal. Este componente (CP-I) está relacionado con la salinidad en el medio y se ve influenciado por el enriquecimiento derivado de la presencia de aguas termales, situación evidenciada en los diagramas de Piper (Figuras $2 b$ y $2 c$ ) y el análisis de relaciones químicas.

Para 2019 (Figura 7a), puede apreciarse que existe una tendencia a la reducción del área de influencia de las puntuaciones altas en la zona norte del área de estudio para el CP-I, aunque sí debe enfatizarse que, por el lado contrario, hay un aumento de 0.07 unidades en el límite superior establecido. Para ambos períodos el comportamiento de predicción determinado es en franjas. Similar tendencia de distribución fue determinada por Yescas-Coronado et al. (2018), en la región de
Comarca Lagunera, para la variable de carbono inorgánico en suelos que reciben enmiendas orgánicas para el desarrollo de actividades agrícolas.

La variable nitrato, que tiene carga negativa en este componente (CP-I), tiende a encontrarse hacia la zona sur de la zona de estudio, muy probablemente, como fue detallado antes en la sección de ACP y de relaciones químicas, por el desarrollo de actividades agrícolas en ella. Sus mayores concentraciones se ubican en los pozos (Tabla 1), que se hallan en el municipio de Tonatico. Con el propósito de complementar, la relación $\mathrm{SO}_{4}{ }^{2-}$ $C t$ ha sido utilizada para medir el impacto de actividades agrícolas. Así pues, 33\% de las muestras presenta una proporción superior a 0.25 (puntos $8,9,10,13$ y 14, Tabla 1), correspondientes a los pozos y a una muestra superficial, indicando la incidencia de la lixiviación de fertilizantes en ellas (Satyaji-Rao et al., 2010). Especial análisis requiere el parámetro cloruros, también asociado positivamente en el CP-I, el cual comúnmente incrementa conforme lo hace la concentración mineral. Este elemento, además de factores geogénicos, puede tener un origen desde el punto de vista antropogénico, como la actividad agrícola que ha sido demostrada en la zona de estudio.

Como elemento de interés, el CP-I está relacionado con el Arsénico (con una carga positiva alta de 0.877). Los resultados presentados en la Tabla 1 demuestran que la presencia de aguas termales en la zona norte está determinando el comportamiento y presencia de arsénico en ella, lo que fue igualmente demostrado en el diagrama de Piper (Figura 2c), es decir, de los procesos de mezcla que tienen lugar en algunas fuentes consideradas no termales, cuya composición tiene características intermedias por el proceso antes mencionado. Consecuentemente, la distribución de este elemento tiene una tendencia decreciente en la dirección noreste-suroeste.

La tendencia del CP-II (Figuras $6 b$ y $7 b$ ), relacionado a alcalinidad, está influenciada positivamente, para el año 2019, con los elementos bicarbonatos, $\mathrm{EpCO}_{2}$, magnesio, calcio y, negativamente, con el $\mathrm{pH}$. A diferencia del comportamiento notado en el CP-I, el CP-II tiende a un 

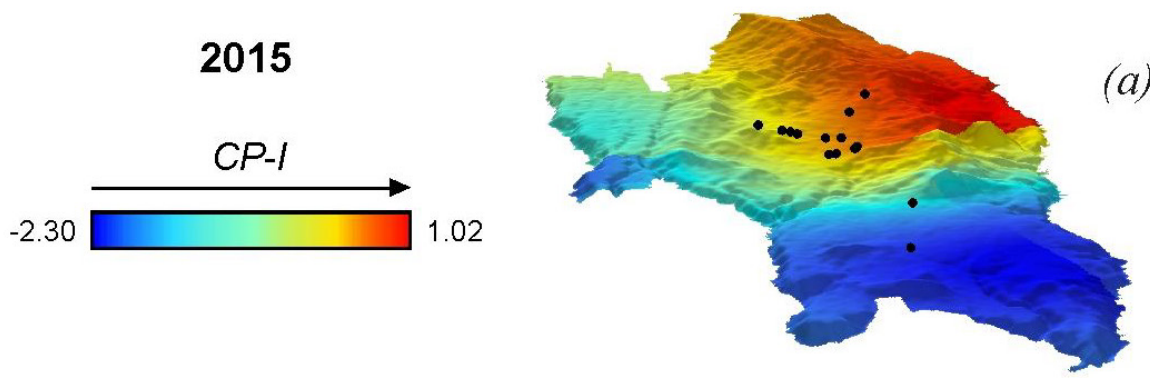

(a)
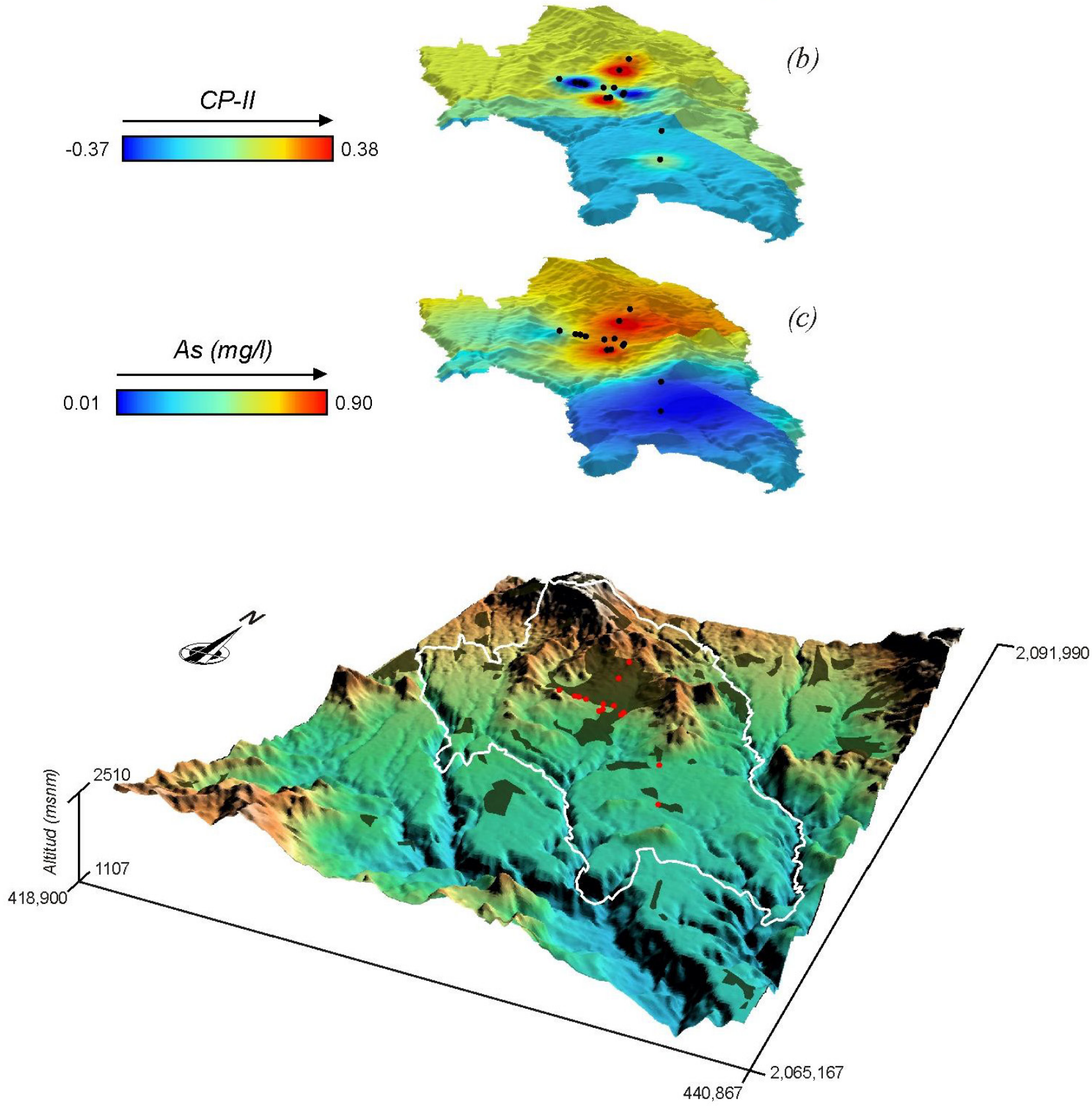

Figura 6 Mapas de distribución espacial, establecidos a partir del kriging ordinario, para las variables (a) CP-I, (b) CP-II y (c) As (mg/I) para el período de muestreo correspondiente al año 2015. 

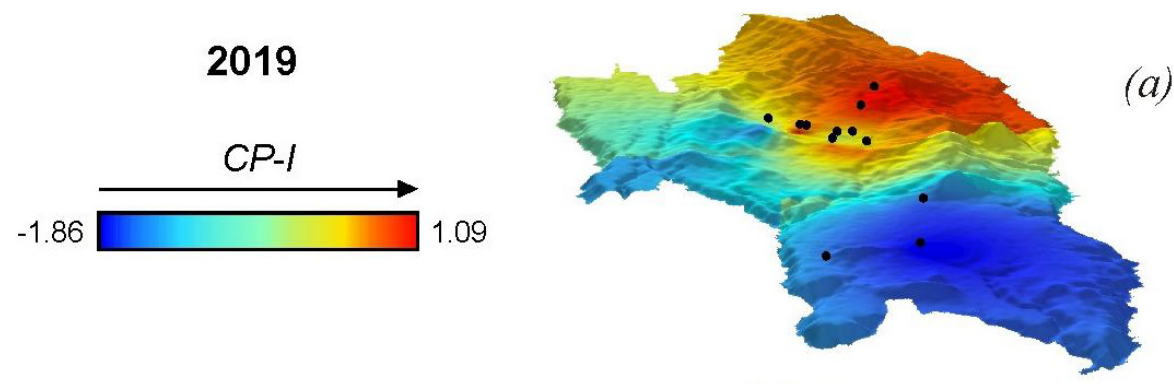

(a)
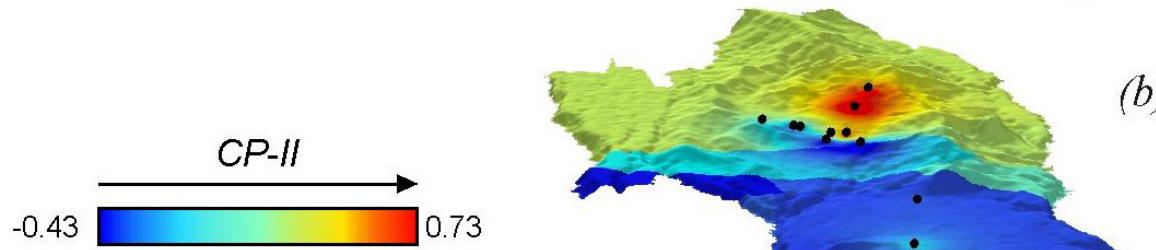

(b)

$-0.43$ 0.73
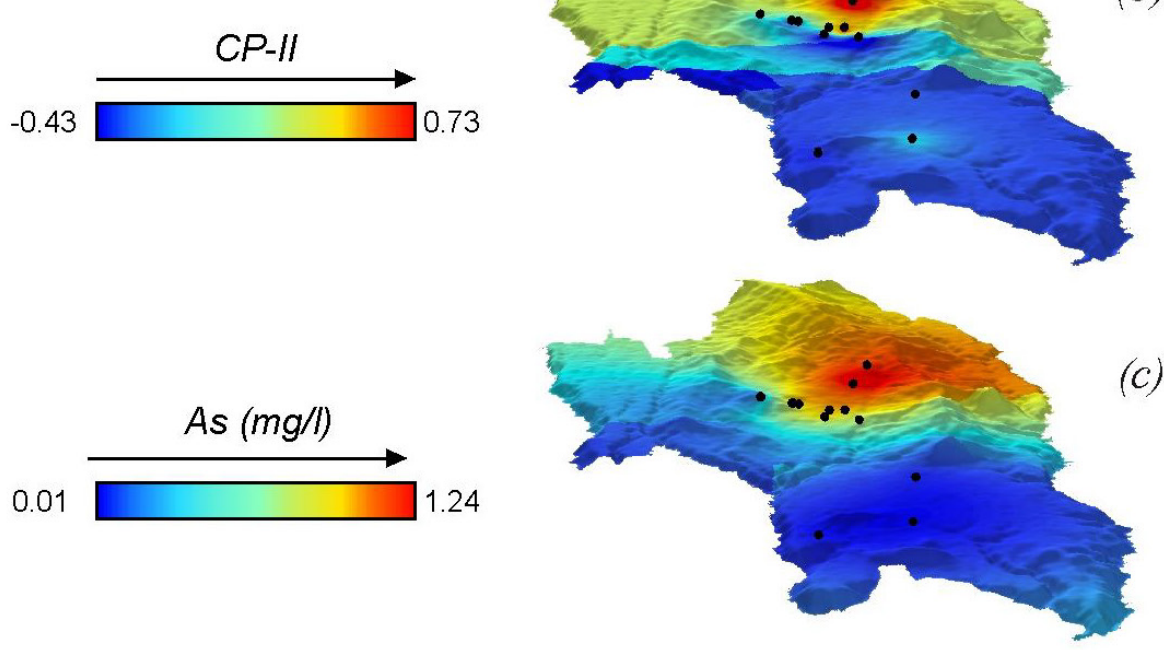

1.24

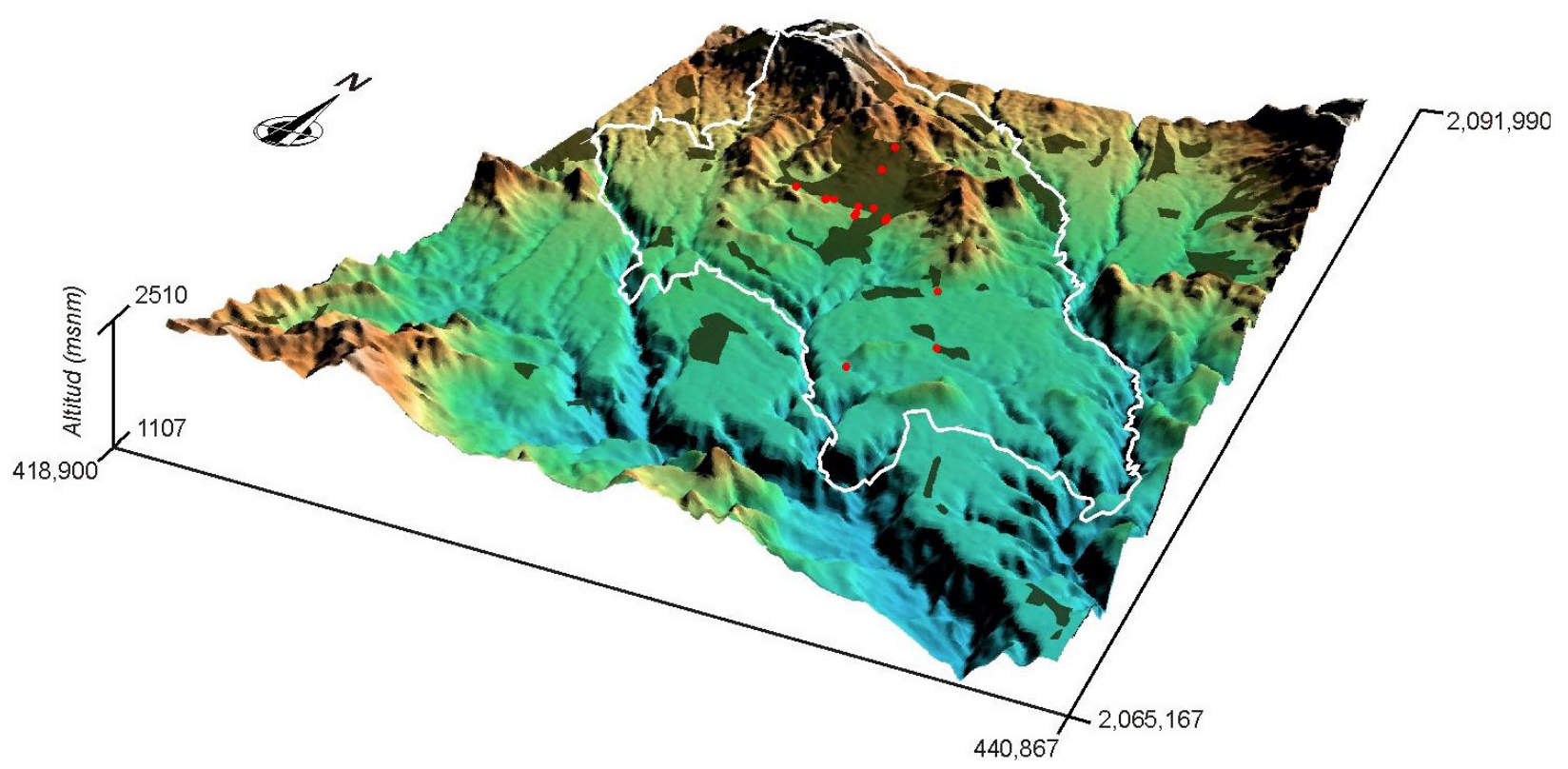

Figura 7 Mapas de distribución espacial, establecidos a partir del kriging ordinario, para las variables (a) CP-I, (b) CP-II y (c) As (mg/l) para el período de muestreo correspondiente al año 2019. 
comportamiento localizado en algunos puntos de la zona de estudio, llegando a las cargas menores, para ambos períodos, hacia la zona central, con el nivel más bajo de -0.37 y -0.43 , para 2015 y 2019, respectivamente.

En cuanto a la predicción de la tendencia de arsénico (Figuras $6 c$ y $7 c$ ), puede decirse que ésta es similar a la encontrada para las variables anteriores, sin embargo, debe enfatizarse un cambio significativo mayor hacia la reducción del área de influencia de las puntuaciones altas, las cuales se concentran hacia el área noreste de la zona de estudio. No obstante, a pesar de lo anterior, existe una variación en la concentración límite máxima, pasando desde $0.90 \mathrm{mg} / \mathrm{l}$, en 2015, hacia 1.24 $\mathrm{mg} / \mathrm{l}$, en 2019 , lo que significaría un aumento en su impacto en la zona. Su tendencia de distribución en franjas es coincidente con el componente principal I. Sánchez-Martos et al. (2001), de manera coincidente con esta investigación, refuerzan la influencia de los factores climáticos en la variación de las superficies de predicción debido a la realización de muestreos de manera previa y posterior a la época de recarga de su zona de estudio.

Teniendo en cuenta la información antes revisada, puede asegurarse que el análisis realizado al interpolar las nuevas variables, los componentes principales (CP-I y CP-II), permite un análisis más completo y sintético, ya que cada una de ellas resume, en sí misma, los elementos fisicoquímicos representativos de influencia en una zona determinada. De esta forma, puede afirmarse, para la zona de estudio, que la calidad del agua decrece en el sentido suroeste-noreste, teniendo al arsénico como principal elemento limitante de calidad en función de su toxicidad. Sin embargo, otros elementos adicionales están igualmente involucrados en la pérdida de la aptitud de uso del recurso para consumo humano.

\section{Conclusiones}

Los resultados obtenidos con la realización del presente estudio sugieren que la composición quí- mica del agua en la zona de estudio depende de diversos factores hidrogeológicos, las condiciones de recarga derivadas de la precipitación, la incidencia del contenido de $\mathrm{CO}_{2}$ y el tiempo de residencia que determina la interacción agua-roca, así como también de las actividades antropogénicas desarrolladas en ella.

En ese sentido, si al complejo análisis derivado de la interacción de los factores anteriormente expuestos se suman las consideraciones, tanto de la alta vulnerabilidad como gran complejidad de estos acuíferos carbonatados, una correcta aproximación hacia su funcionamiento y sus mecanismos de composición fisicoquímica, puede ser lograda, únicamente, a partir de una perspectiva variada de técnicas analíticas.

Partiendo de estas circunstancias particulares, y como una forma de complementar la información lograda mediante herramientas clásicas de análisis hidrogeoquímico utilizadas en el estudio de acuíferos kársticos, esta investigación optó por la implementación de una metodología combinada para identificar los principales mecanismos que influencian la composición fisicoquímica del agua, así como su evolución espacio-temporal en la zona de estudio.

Dicha composición, determinada a través del diagrama de Piper, puede ser clasificada, para ambos períodos de muestreo, en tres tipos: $\mathrm{Ca}^{2+}-\mathrm{HCO}_{3}^{-}, \mathrm{Na}^{+}-\mathrm{Cl}^{-}$y $\mathrm{Ca}^{2+}-\mathrm{Mg}^{2+}-\mathrm{Cl}$. Estas facies hidroquímicas estarían evidenciando, para la zona de estudio, procesos de disolución de minerales carbonatados, como la dolomita y la calcita. Sin embargo, el análisis hidroquímico demuestra la influencia de la disolución de otros minerales, tales como sulfato de magnesio, halita, silicatos y materiales evaporíticos en la conformación fisicoquímica del agua, así como de tres procesos adicionales que determinan, en función de la época, el grado de mineralización de las fuentes: (1) el intercambio catiónico, (2) la mezcla de aguas termales y no termales y (3) la dedolomitización.

El sistema estudiado está caracterizado por la incidencia de concentraciones variables de sulfatos, oscilando desde 15.2 hasta $956.7 \mathrm{mg} / \mathrm{l}$, donde 
las altas concentraciones de este compuesto coinciden con las fuentes de alta salinidad, influenciadas por la presencia de aguas termales. El promedio de sulfatos para las fuentes con potencialidad para consumo humano, pozos y fuentes no termales, no excede el límite máximo permisible vigente de 250 $\mathrm{mg} / \mathrm{l}$, siendo afectadas de forma negativa, respectivamente, por los nitratos y arsénico, que exceden las normas establecidas internacionalmente, por lo que deberían ser tratadas antes de ser utilizadas para su consumo.

La técnica de estadística multivariada aplicada a los datos de composición fisicoquímica del agua, realizada por Análisis de componentes principales, aportó información acerca de las diferencias litológicas, del sistema de flujo y de las condiciones hidrogeológicas de la zona de estudio. De este modo, se pudo confirmar e individualizar los procesos predominantes en ella, así como agrupar los sitios con características similares que podrían estar siendo afectados por procesos análogos en su composición química, los cuales demuestran la heterogeneidad del acuífero.

Factores antropogénicos de enriquecimiento de nutrientes, la mineralización con elementos nocivos de origen geogénico y la participación de minerales carbonatados en la composición fisicoquímica del agua fueron asociados a los dos componentes principales extraídos en el análisis estadístico multivariado. Este análisis permitió, de manera simultánea, la identificación de los parámetros $\mathrm{pH}$ y $\mathrm{EpCO}_{2}$ como prioritarios para entender la evolución de los procesos de mineralización de las fuentes considerando la naturaleza carbonatada de la zona de estudio. Esta técnica estadística permitió la confirmación de tres posibles mecanismos involucrados en la presencia/ liberación de arsénico en la zona de estudio: (1) la presencia de aguas termales, (2) la degradación de la materia orgánica y (3) la participación del pH en el enriquecimiento iónico del agua.

Las técnicas de geoestadística son una herramienta útil para la evaluación de la variación espacial y temporal de los procesos hidrogeoquímicos que tienen lugar en la zona de estudio.
En ese sentido, el análisis variográfico muestra que existe un claro patrón de distribución de los factores que determinan la composición química del agua. Este análisis ofreció la base para la generación de información pertinente respecto del riesgo de la incidencia de arsénico, como elemento de interés, llevando así a concluir que la calidad de agua se reduce en el sentido geográfico sur-oeste hacia nor-este. Esta distribución podría estar relacionada con el sistema de fallas existente en la zona de estudio, las cuales determinan el flujo emergente de aguas termales en la zona de Ixtapan de la Sal, estableciendo las variaciones estacionales en las concentraciones de este elemento en el agua con potencial para consumo humano.

Investigaciones futuras en la zona deberán contemplar dos aspectos para mejorar los resultados logrados en este estudio, en el entendido de obtener herramientas mejoradas para el aprovechamiento del recurso: (1) la ampliación, tanto del número como del área geográfica cubierta por los sitios de muestreo, mejorando con ello los resultados de las técnicas de estadística multivariada y geoestadística empleadas y (2) la profundización en el estudio de la influencia del uso del suelo que, como factor antropogénico de enriquecimiento, restringe la calidad del agua en el sistema.

Puede establecerse como conclusión general que, de manera coincidente con otros autores, el abordaje multienfoque desarrollado en esta investigación, basado en diferentes técnicas hidrogeoquímicas y estadísticas, se considera la alternativa más viable para el estudio de la evolución espacio-temporal de la calidad del agua en este sistema kárstico. Este abordaje se considera como el principal aporte realizado desde esta investigación en la zona de estudio, puesto que contribuye un enfoque por primera vez utilizado en la misma. Este hecho permite fortalecer la comprensión de los mecanismos predominantes involucrados en la composición fisicoquímica del agua, factor encaminado hacia el establecimiento de una gestión adecuada del recurso en los municipios de Ixtapan de la Sal y Tonatico. 


\section{Agradecimientos}

Los autores desean agradecer a la Universidad Autónoma del Estado de México por el soporte de esta investigación, así como al Laboratorio de Calidad del Agua del Instituto Interamericano de Tecnología y Ciencias del Agua, por el apoyo provisto para la realización de los análisis químicos del agua, llevados a cabo en sus instalaciones. De igual manera, muestras de agradecimiento de los autores van dirigidas hacia el CONACYT que, a través del otorgamiento de las becas y el apoyo financiero, hizo posible el desarrollo de esta investigación.

\section{Referencias}

Ali W., Rasool A., Junaid M., Zhang H., 2019, A comprehensive review on current status, mechanism, and possible sources of arsenic contamination in groundwater: a global perspective with prominence of Pakistan scenario: Environmental Geochemical Health, 41, 737-760. https://doi. org/10.1007/s10653-018-0169-x

Ali-Mert, B., Dag, A., 2017, A Computer Program for Practical Semivariogram Modeling and Ordinary Kriging: A Case Study of Porosity Distribution in an Oil Field: Open Geoscience, 9(1), 663-674. https://doi. org/10.1515/geo-2017-0050

Avilés M., Garrido SE., Esteller MV., De La Paz JS., Najera c., Cortés J., 2013, Removal of groundwater arsenic using a household filter with iron spikes and stainless Steel: Journal of Environmental Management, 131, 103-109. https://doi.org/10.1016/j. jenvman.2013.09.037

Cardenal J., Benavente J., Cruz-SanJulián J.J., 1994, Chemical evolution of groundwater in Triassic gypsum-bearing carbonate aquifers (Las Alpujarras, southern Spain): Journal of Hydrology, 161, 3-30. https://doi. org/10.1016/0022-1694(94)90119-8
Cerón, J.C., Martín-Vallejo, M., García-Rossell, L., 1998, Geoquímica de las Aguas Termales con $\mathrm{CO}_{2}$ del SE de las Cordilleras Béticas: Estudios Geológicos, 54, 199-207.

DeVore, C.L., Rodriguez-Freire L., Mehdi-Ali, A., Ducheneaux, C., Artyushkova, K., Zhou Z., Latta, D.E. Lueth, V.W., Gonzales, M., Lewis, J., Cerrato, J.M., 2019, Effect of bicarbonate and phosphate on arsenic release from mining-impacted sediments in the Cheyenne River watershed, South Dakota, USA: Environmental Science: Processes Impacts, 21, 456-468. https://doi. org/10.1039/c8em00461g

Ebrahimi, K.H., Ausati, K.H., Feiznia, S., JannatRostami, M., 2011, Assessing Temporal and Spatial Variations of Groundwater Quality (A case study: Kohpayeh-Segzi): Journal of Rangeland Science, 1(3), 193-202.

Esteller, M.V., Martínez-Florentino, A.K., Morales-Reyes, G.P., Cardona, A., Expósito, JL., 2019, Mixing processes between thermal waters and non-thermal waters: a case study in Mexico: Environmental Earth Sciences, 78, 295. https://doi.org/10.1007/ s12665-019-8311-3

Gárfias, J., Aravena, R., Arroyo, N., 2010, Hydrochemistry and origins of mineralized waters in the Puebla aquifer system, Mexico: Environmental Earth Science, 59, 1789-1805. https://doi.org/10.1007/ s12665-009-0161-y

Gorai, A.K., Kumar, S., 2013, Spatial Distribution Analysis of Groundwater Quality Index Using GIS: A Case Study of Ranchi Municipal Corporation (RMG) Area: Geoinformatics \& Geostatistics: An Overview, 1(2), 1-11. https://doi. org/10.4172/2327-4581.1000105

Gupta, S., Gupta, V., 2013, Speciation and toxicity of arsenic: A human carcinogen: Research Journal of Recent Sciences, 2(ISC-2012), 45-53.

Hair, JF., Black, WC., Babin, BJ., Anderson, RE., 2014, Exploratory Factor Analysis, en 
Pearson, 7(ed.), Multivariate Data Analysis: Harlow, Pearson Education Limited, 89-150. Halim, MA., Majumder, RK., Nessa SA., Oda K., Hiroshiro Y., Jinno, K., 2010, Arsenic in shallow aquifer in the eastern region of Bangladesh: insights from principal component analysis of groundwater compositions: Environmental Monitoring and Assessment, 161, 453-472. https://doi. org/10.1007/s10661-009-0760-9

Homaee, M., Dirksen, C., Feddes, R.A., 2002, Simulation of root water uptake: I. NonUniform transient salinity using different macroscopic reduction functions: Agricultural Water Management, 57(2), 89-109. https:// doi.org/10.1016/s0378-3774(02)00072-0

Jalali, M., 2005, Major Ion chemistry of Groundwaters in the Bahar Area, Hamadan, Western Iran: Environmental Geology, 47, 763-772. https://doi.org/10.1007/ s00254-004-1200-3

Jeong, C.H., 2001, Effect of land use and urbanization on hydrochemistry and contamination of groundwater from Taejon area, Korea: Journal of Hydrology, 253, 194-210. https://doi.org/10.1016/ s0022-1694(01)00481-4

Jiang, Y., Guo, H., Jia, Y., Cao, Y., Hu, C., 2015, Principal component analysis and hierarchical cluster analyses of arsenic groundwater geochemistry in the Hetao basin, Inner Mongolia: Chemie der Erde, 75, 197-205. https://doi.org/10.1016/j. chemer.2014.12.002

Juan-Pérez, J., 1994, La hidrogeoquímica y su aplicación en la región de Ixtapan de la SalTenancingo, Estado de México: México, Universidad Nacional Autónoma de México, Tesis de maestría, $150 \mathrm{p}$.

Kim, K., Rajmohan, N., Kim, H., et al., 2004, Assessment of groundwater chemistry in a coastal region (Kunsan, Korea) having complex Contaminant Sources: A Stoichiometric Approach: Environmental Geology, 46, 763-774. https://doi. org/10.1007/s00254-004-1109-x
López-Chicano, M., Bouamama, M., PulidoBosch, A., Vallejos, A., 2001, Factors which determine the hydrogeochemical behaviour of karstic springs. A case study from the Betic Cordilleras, Spain: Applied Geochemistry, 16, 1179-1192. https://doi.org/10.1016/ s0883-2927(01)00012-9

Ma, R., Gui, C., Liu, J., Shi, J., 2014, Combined Use of Multivariate Statistical and Hydrochemical Analysis for Groundwater Quality Evolution: A case study in North Chain Plain: Journal of Earth Science, 25(3), 587-597. https://doi.org/10.1007/ s12583-014-0446-2

Martínez-Florentino, T.A.K., 2015, Caracterización Hidrogeoquímica del Sistema de Manantiales Termales de Ixtapan de la Sal-Tonatico: Estado de México, México, Universidad Autónoma del Estado de México, Tesis maestría, 130 p.

McLeod, L., Bharadwaj, L., Epp, T., Waldner, C.L., 2017, Use of Principal Components Analysis and Kriging to Predict GroundwaterSourced Rural Drinking Water Quality in Saskatchewan: International Journal of Environmental Research and Public Health, 14(1065), 1-25. https://doi.org/10.3390/ ijerph14091065

Meybeck, M., 1987, Global Chemical Weathering of Surficial Rocks Estimated from River Dissolved Loads: American Journal of Science, 287, 401-428. https://doi. org/10.1016/0198-0254(87)95902-4

Minvielle, S., Lastennet, R., Denis, A., Peyraube, N., 2015, Characterization of karst systems using SIc-P $\mathrm{PCO}_{2}$ method coupled with PCA and frequency distribution analysis. Application to karst systems in the Vaucluse County (Southeastern France): Environmental Earth Sciences, 74, 7593-7604. https://doi. org/10.1007/s12665-015-4389-4

Nas, B., Berktay, A., 2010, Groundwater quality mapping in urban groundwater using GIS: Environmental Monitoring and Assessment, 160, 215-227. https://doi.org/10.1007/ s10661-008-0689-4 
Neal, C., House, W.A., Down, K., 1998, An Assessment of excess carbon dioxide partial pressures in natural waters based on $\mathrm{pH}$ and alkalinity measurements: Science of the Total Environment, 210/211, 173-185. https:// doi.org/10.1016/s0048-9697(98)00011-4

Ortega-Guerrero, MA., 2009, Presencia, distribución, hidrogeoquímica y origen de arsénico, fluoruro y otros elementos traza disueltos en agua subterránea, a escala de cuenca hidrológica tributaria de LermaChapala, México: Revista Mexicana de Ciencias Geológicas 26 (1): 143-161.

Pacheco-Avila J., Cabrera-Sansores A., Pacheco Castro R., Ye M., 2017, Groundwater Quality: analysis of its temporal and spatial Variability in a Karst Aquifer: Groundwater, 56(1), 62-72. https://doi.org/10.1111/ gwat. 12546

Rasool, A., Farooqi, A., Xiao, T., Masood, S., Kamran, M. A., 2016, Elevated levels of arsenic and trace metals in drinking water of Tehsil Mailsi, Punjab, Pakistan: Journal of Geochemical Exploration, 169, 89-99. https://doi.org/10.1016/j. gexplo.2016.07.013

Sánchez, D., Barbera, JA., Mudarra, M., Andreo, B., 2015, Hydrogeochemical tools applied to the study of carbonate aquifers: examples from some karst systems of Southern Spain: Environmental Earth Sciences, 74, 199-215. https://doi.org/10.1007/ s12665-015-4307-9

Sánchez-Martos, F. Jiménez-Espinosa, R., Pulido-Bosch, A., 2001, Mapping groundwater quality variables using PCA and geostatistics: a case study of Bajo Andarax, southeastern Spain: Hydrological Sciences Journal, 46(2), 227-242. https:// doi.org/10.1080/02626660109492818

Satyaji-Rao, Y.R., Gosain, A.K., Keshari, A.K., 2010, Evaluation of regional groundwater quality using PCA and geostatistics in the urban coastal aquifer, East Coast of India: International Journal Environment and Waste Management, 5 (1/2), 163-180. https://doi. org/10.1504/ijewm.2010.029700
Subba-Rao, N., Prakasa-Rao, J., Subrahmanyam, A., 2007, Principal Component Analysis in Groundwater Quality in a Developing Area of Andhra Pradesh: Journal Geological Society of India, 69, 959-969.

Subyani, A.M., Al-Ahmadi, M.E., 2010, Multivariate Statistical Analysis of Groundwater Quality in Wadi Ranyah, Saudi Arabia: Journal of King Abdulaziz University: Earth Sciences, 21(2), 29-46. https://doi.org/10.4197/ear.21-2.2

Srinivas, Y., Aghil, TB., Hudson Oliver, D., Nair, N., Chandrasekar, N., 2017, Hydrochemical characteristics and quality assessment of groundwater along the Manavalakurichi coast, Tamil Nadu, India: Applied Water Science, 7, 1429-1438. https://doi. org/10.1007/s13201-015-0325-8

Valdes, D., Dupont, JP., Laignel, B., Ogier, S., Leboulanger, T., Mahler, Bj., 2007, A spatial analysis of structural controls on Karst groundwater geochemistry at a regional scale: Journal of Hydrology, 340, 244-255. https:// doi.org/10.1016/j.jhydrol.2007.04.014

Webster, R., Oliver, M.A., 2014, A tutorial guide to geostatistics: Computing and modelling variograms and kriging: Catena, 113, 56-69. https://doi.org/10.1016/j. catena.2013.09.006

World Health Organization (WHO), 2011, Guidelines for drinking water quality, 4th edn. World Health Organization, Geneva, 564 p.

Yescas-Coronado, P., Álvarez-Reyna, V.D.P., Segura-Castruita, M.A., García-Carrillo, M., Hernández-Hernández, V., GonzálezCervantes, G., 2018, Variabilidad Espacial del Carbono Orgánico e Inorgánico del Suelo en la Comarca Lagunera, México: Boletín de la Socidead Geológica Mexicana, 70 (3), 591 - 610. https://doi.org/10.18268/ bsgm2018v70n3a2

Zheng, Y., Stute, M., Van Geen, A., Gavrieli, I., Dhar, R., Simpson, H.J., 2004, Redox control of arsenic mobilization in Bangladesh groundwater: Apllied Geochemistry, 19, 201-214. https://doi.org/10.1016/j. apgeochem.2003.09.007 